\title{
The Great Depression in Belgium from a Neoclassical Perspective
}

L. Pensieroso

Discussion Paper 2007-25

Département des Sciences Économiques

de l'Université catholique de Louvain 


\title{
The Great Depression in Belgium from a Neoclassical Perspective*
}

\author{
Luca Pensieroso ${ }^{\dagger}$
}

July 17, 2007

\begin{abstract}
This paper casts the Belgian Great Depression of the 1930s within a dynamic stochastic general equilibrium (DSGE) framework. Results show that a total factor productivity shock within a standard real business cycle model is unsatisfactory. Introducing war expectations in the baseline model produces little improvement. Given the evidence on sticky wages put forward by historians, it shows that a simple DSGE model with sticky wages à la Taylor improves on the results.
\end{abstract}

Keywords: Great Depression, Belgium, sticky wages, dynamic stochastic general equilibrium

JEL Classification: E13, N14

\section{Introduction}

Following the seminal work of Cole and Ohanian (1999), recent studies have started to apply general equilibrium analysis to the Great Depression of the

\footnotetext{
*Part of this paper was written when I was a visiting scholar at GREMAQ - Université des Sciences Sociales Toulouse 1. I thank Franck Portier for his supervision of this work. David de la Croix, Michel De Vroey, Henri Sneessens and Raf Wouters made useful comments on an earlier draft. I have also benefited from discussions with Anna Batyra, Raouf Boucekkine and Giulio Nicoletti. Michel Juillard helped me with the Dynare software. All the remaining errors are mine. Financial support from the Belgian French-speaking Community (Grant ARC 03/08-302 "New Macroeconomic Perspectives on Development"), from the Belgian Federal Government (Grant PAI P6/07 "Economic Policy and Finance in the Global Equilibrium Analysis and Social Evaluation"), and from the Belgian FNRS is gratefully acknowledged.

${ }^{\dagger}$ Department of Economics and IRES, Université catholique de Louvain. E-mail: luca.pensieroso@uclouvain.be
} 
1930s. ${ }^{1}$ The aim of this stream of research is to deepen our historical knowledge of the period, by putting the quantitative tools provided by modern macroeconomics at the service of historic analysis. ${ }^{2}$

This paper follows the tradition of this literature, casting the Great Depression in Belgium within a dynamic stochastic general equilibrium (DSGE) framework. A typical aspect of this literature is its focus on a purely national dimension. Among all the papers interpreting the Great Depression by means of a DSGE model, only two - Cole, Ohanian, and Leung (2005) and Perri and Quadrini (2002) - have taken a worldwide perspective. Even studies concerning notoriously open economies such as France (Beaudry and Portier (2002)), Germany (Fisher and Hornstein (2002)) and the United Kingdom (Cole and Ohanian (2002)) took a closed-economy perspective. If, a priori, such a stance appears unwarranted, it is nonetheless true that these analyses still delivered useful insights, while keeping the models relatively simple. On this ground, although the closed-economy assumption may be difficult to retain for Belgium, it is useful to proceed stepwise for analytical convenience: first a closed-economy analysis, and then the exploration of the open-economy issues. This paper deals mainly with the former, leaving the open-economy analysis for future research. However, a brief detour into the open-economy field is provided in the last section as a robustness check.

The paper is organised as follows. In Section 2, I look at selected data on interwar Belgium. Section 3 provides some basic facts about the Belgian interwar history. In Section 4, I detrend the data so as to make them compatible with the theory. Section 5 derives and simulates a basic real business cycle (RBC) model with productivity shocks, to account for the Great Depression in Belgium. Section 6 extends the analysis by introducing war expectations in the baseline model. Results suggest that, in a perfectcompetition, flexible-price framework, the contribution of both productivity shocks and war expectations for explaining the depression is slim. Therefore, in Section 7, I consider a simple DSGE model with nominal wage stickiness and monetary shocks. Results show that the introduction of nominal wage staggering and monetary shocks improves the results, with the model able to account for all the observed drop in detrended output, consumption, investments and labour input. The sluggishness of the recovery, however, remains largely unexplained. The role of total factor productivity (TFP) shocks in this new environment is also explored. Its contribution is again found to

\footnotetext{
${ }^{1}$ Major contributions in this field are Cole and Ohanian (2004), Christiano, Motto, and Rostagno (2004), Kehoe and Prescott (2002), Prescott (1999) and Weder (2006), to name but a few. Pensieroso (2007) provides a critical survey of this literature.

${ }^{2}$ On the clash between economic history and new classical macroeconomics over the Great Depression, see De Vroey and Pensieroso (2006).
} 
be minor. Section 8 removes the closed-economy assumption from the basic RBC model. Although this framework is admittedly oversimplified, its results are almost identical with those for the closed-economy. This finding suggests that, in the perfect-competition, flexible-price RBC model at least, the tiny additional explanatory power gained by considering an openeconomy model is not worth the price of having an analytically less tractable model. Finally, Section 9 draws some conclusions, and provides guidelines for future research.

\section{A look at the Data}

In this section I will present selected data on the Belgian interwar economy. The appendix describes the sources and derivation of the data in detail.

Figure 1 shows real data on output and its components. GNP $(Y)$ growth witnessed two accelerations, in 1922-24 and 1928-30. The Great Depression hit Belgium in 1931, later than in most other countries. Output decreased until 1934, recovered until 1937, then decreased again. Consumption followed a comparable but slightly smoother pattern. Figure 2 shows investments $(I)$, imports $(M)$, exports $(X)$ and public consumption $\left(G_{c}\right)$ as percentages of GNP. Investments as a percentage of GDP swing widely, with a marked downward tendency: decreasing until 1926, increasing until 1929, then decreasing again. In 1939, investment comprised just $8.4 \%$ of GNP, compared with a value of $19.7 \%$ in 1920. Exports as a percentage of GNP increased sharply until 1928, then decreased until 1932, then increased again until 1937. Imports as a percentage of GNP was basically increased until 1931, and then again from 1932 to 1937, but saw two big drops in 1932 and 1938. It is worth highlighting that the percentages of exports and imports are relatively high, reaching a level as high as $30 \%$ of GNP. Trade balance (i.e. exports minus imports) was in deficit during all the 1920s except 1926-1928, and was in deficit again in 1929-1935. However there was then a moderate surplus until the end of the decade. Public consumption's share of GNP decreased slightly until 1927, and increased slightly afterwards. As shown in Figure 3, private consumption increased sharply as a percentage of GNP from 1920 to 1922, but to decreased steadily thereafter until 1929. It then went up again until 1932, and later swing up and down with a slightly decreasing trend.

Figure 4 gives monthly data on real interest rates $(r)$ and unemployment rates $(u)$. Real interest rates were positive and high in the early 1920s and then in the midst of the depression years. They were low and even negative in the mid-twenties and in 1936-37. As for unemployment, Belgium seems to have experienced a full employment in the 1920s, apart from 1920-21, 
when recovery from the war had not yet been fully attained. After 1930, unemployment rapidly gained momentum. It reached a peak of $28 \%$ in 1935 , followed by a mild and slow recovery, to worsen again in 1938-39.

Figure 5 shows 1930-based indices of real and monetary wages. Monetary wages sharply increased during all the 1920s, to reach a peak in 1930 . Then they decreased during the depression, reaching a trough in 1935, when they had decreased cumulatively by a good $24 \%$. Thereafter, they increased again until the outbreak of the war. Real wages followed a different pattern. They were almost constant and then slightly decreasing up to 1927, but increased appreciably thereafter. In the midst of the depression, real wages remained approximately constant, at slightly above their 1930 value. After 1935, they increased again until 1939.

Figure 6 shows the monthly retail price index, as well as its monthly rate of variation. Belgium witnessed an appreciable deflation in 1920-21, followed by period of steep increases in the price index up to 1925. After mid-1926, prices shot up, possibly as a consequence of the monetary stabilisation carried out in that year. Thereafter, inflation follows the same path as in 1923-26, until 1930. As the Great Depression hit Belgium, the sharp deflation typically associated with it followed. Deflation endured up to 1935, the year of the devaluation of the Belgian franc.

To better appreciate the possible role of monetary variables, Figure 7 shows data for the nominal money supply $(M 1)$, together with the annual price index $(P)$. From this graph we see that money supply increased until 1931, then decrease sharply until 1934, then increased again. The behaviour of the real money supply can be deduced by comparing the nominal money supply index with the price index. The exercise shows that, as far as the Great Depression is concerned, the real quantity of money decreased in 1932, in 1934 and in 1937, as in those years the nominal quantity of money dropped more than the price level.

Figure 8 gives the data on nominal exchange rates between the Belgian franc and the British, American and French currencies. The Belgian franc depreciated against the pound from 1919 to 1927. It then stayed constant four years, to appreciate again from 1931 to 1934. Thereafter it depreciated again until 1936. The exchange rate between the Belgian franc and the dollar followed a similar though less accentuated path. In this case, the appreciation of the franc in the 1930s started later, in 1933. Finally, the Belgian franc depreciated against the French franc from 1919 to 1923, to appreciate until 1926. It fell sharply in 1927 , depreciating by $40 \%$, to stay constant until 1934, when it fell sharply again, followed in 1936 by a strong appreciation. 


\section{History of Interwar Belgium}

In this section I shall briefly outline the basic economic and political events that shaped Belgium's interwar history. ${ }^{3}$

\section{$3.1 \quad 1920-1926$}

Unlike other European nations, Belgium had a low debt burden to cope with after World War I. In fact, having experienced German occupation throughout most of the war, Belgium had had no possibility of issuing internal debt for war financing. This is why, initially, the Belgian economy skipped the typical debt-driven post war hyperinflation which hit other countries. The 1920-1926 period witnessed a marked post-war growth in an environment characterised by inflation, a floating exchange rate, low unemployment rates and steady real wages.

According to the historians, the division of the reconstruction burden between labour and capital income was controversial, a trait that Belgium shared with many other European countries immediately after the war. Much like the French, the Belgians tried to avoid the problem by pretending to believe that Germany would pay for the reconstruction of their economy, as it was obliged to by the Versailles Treaty. By sticking to this conviction, they produced big government deficits, financing both the reconstruction and a new social legislation by issuing public-debt short run bonds. Actually this deficit spending was concealed by the fact that, at that time, the Belgian government kept two budgets, one, which was more and less always balanced, for ordinary expenses, and another, whose liabilities were supposed to be paid by the Germans, for extraordinary expenses. After the French invasion of the Ruhr failed (1923), this double accounting trick did not work anymore. Investors realised that Germany would never pay for Belgian reconstruction and started to withdraw their money. The Belgian franc depreciated from $30 \mathrm{BF} / £$ in 1919 to $96 \mathrm{BF} / £$ in 1925 . Inflation rose. If the exchange rate were to be stabilised and the gold standard restored, new taxes had to be raised, to control the public debt, thus restoring investors' trust. After a first failed attempt in 1925, the franc was finally stabilised in 1926. The new government was able to take draconian fiscal measures, to restore the budgetary balance, including the levying of new taxes on land and luxury consumption, and the restructuring of the railway system. Under these new

\footnotetext{
${ }^{3}$ Sources are Baudhuin (1946), Cassiers (1989b), Cassiers (1995), Eichengreen (1992), Goossens (1988), Goossens, Peeters, and Pepermans (1988), Hogg (1986), Mommen (1994), and Vanthemsche (1987).
} 
conditions, an international loan was obtained, which allowed the National Bank to stabilise the franc at the rate of $175 \mathrm{BF} / £$.

\section{$3.2 \quad 1926-1930$}

In the period between 1926 and 1930, the Belgian economy experienced high growth rates. However, there is some evidence that such a growth was not evenly distributed among sectors. In particular, the wholesale and the retail price indices followed different patterns, with retail prices increasing much faster than wholesale prices. According to Cassiers (1995), this shows that the price in francs of tradable goods stopped growing soon after the stabilisation of the franc, whereas domestic prices kept on increasing. This led to a decline in profitability in the export sector. This observation is reinforced by the fact that real wages grew by about 20\% between 1927 and 1930. Notwithstanding this, unemployment rates were remarkably low until the end of 1930.

Another feature of the period is the marked surge in banking and financial activities. Prices on the stock exchange grew on average by $246 \%$ between August 1926 and May 1928, apparently fueled by a generalized distrust of public securities. Banks' liabilities increased by 50\% between 1927 and 1930, without a comparable increase in their capitalisation. After the stabilisation, there was a heavy inflow of gold, which induced the National Bank to adopt sterilisation policies.

In synthesis, the 1926-1930 was a period of boom in the domestic and financial sectors, while profitability in the export sector fell because of the combination of decreasing output prices and increasing unit labour costs.

\section{$3.3 \quad 1930-1935$}

In 1931, the United Kingdom, one of Belgium's biggest commercial partners, left the gold standard and devaluated the pound. The United Kingdom also imposed trade restrictions on steel and other goods that hit Belgium heavily. Belgian exporters reacted as price-takers typically do, i.e. by trying to sustain losses rather than losing market share. The volume of exports therefore fell much less than their value in Belgian francs.

When the United Kingdom left the gold standard, the Belgian authorities implemented deflationary policies in order to reduce the differential between domestic and external prices. Income tax, indirect taxes and tariffs were all increased. The real tax burden, which was $11.7 \%$ in 1930, jumped to $15.3 \%$ in 1932 and $16.4 \%$ in 1934. Public expenditure on salaries, pensions and unemployment benefits were reduced. Nominal wages went down but not 
enough to prevent real wages increasing. The unemployment rate jumped from $4 \%$ in 1930 to above $20 \%$ in 1932 . The fragile bank system entered a liquidity crisis soon after 1933. In 1934 the Banque Nationale Belge du Travail declared solvency problems. The National Bank reduced the official discount rate so as to inject liquidity into the system. But this policy to save the financial system went openly against gold standard rules, as big gold outflows were being observed, to which the National Bank should have reacted by increasing the discount rate. Investors started liquidating deposits, as they anticipated a devaluation of the franc. This worsened the bank crisis and made eventual devaluation unavoidable. After a year of political and financial turmoil, the Belgian government devaluate the franc by $28 \%$ on April 1935. The amount was intended to regain competitive prices abroad, while avoiding a competitive devaluation that could have caused commercial retaliations from the United Kingdom.

\section{$3.4 \quad 1935-1939$}

Devaluation was followed by a big credit expansion, which permitted to a recovery till 1937. Pressure on aggregate demand caused inflation to gain momentum. Yet capacity was apparently so under-utilised that inflation remained under control. Mutatis mutandis, the same was true for real wages, which were kept under control, although they increased gradually. The Belgian authorities, unlike their French counterparts, were initially able to resist the 40-hours-a-week movement. Unemployment remained very high, compared to 1930. Finally, currency devaluation notwithstanding, the trade account did not improve. In facts, exports stagnated, whereas imports increased, possibly due to the upsurge in aggregate demand. Strong capital inflows helped to keep the balance of payments favourable.

\section{The Data through the Lens of the Theory}

\subsection{Detrending}

According to RBC theory, business cycles are defined as deviations from the long run trend. This means that to be able to look at the Great Depression in Belgium from a neoclassical perspective, I first need to remove the long-run trend from the data. ${ }^{4}$ Following Cole and Ohanian (1999), I have assumed

\footnotetext{
${ }^{4}$ It is worth highlighting that detrending is hardly a neutral technique, in the sense that by construction the choice of the trend value can influence the magnitude and even the presence of cyclical oscillations.
} 
that the economy grows in the long-run as predicted by the simple SolowRamsey framework, so that all per-capita variables grow at the same constant rate, which is the exogenous growth rate of technology. Using data from Comin and Hobijn (2004), I computed the average rate of growth of the Belgian real GDP per capita in the period 1900-1994 $(\mathrm{g})$, excluding World Wars I and II, and the Great Depression (1929-1939) as well. It turned out to be equal to $3.02 \%$. This is assumed to be the long-run constant growth rate. Next I collected data on the Belgian working-age population (i.e. the 15-65 demographic cluster) from the Belgian official demographic statistics (Ministere des Affaire Economiques (1943)) and I expressed GNP in per capita terms $(Y / N=y)$. Hence, I detrended the $y$ series, taking 1929 as base-year (i.e. $1929=t_{0}$ ), and using the following formula

$$
\tilde{y}_{t}=\frac{y_{t}}{\gamma^{\left(t-t_{0}\right)}}
$$

where $\gamma=1+g$. The same procedure was followed for detrending all the macroeconomic aggregates.

The results are shown in Figure 9. Output per capita dropped a good $20 \%$ after 1930, and remained at about this level, with a further decrease in 1938-39. In line with Cole and Ohanian (1999)'s claim about the US Great Depression, Belgium did not recover before the outbreak of world war II. Investments per capita $(i)$ constantly decreased, to reach the trough of almost $64 \%$ below trend in 1939 . Consumption per capita $(c)$ was below trend throughout the depression years, showing a slight downward trend.

\subsection{Total Factor Productivity}

Figure 9 also shows the detrended total factor productivity (TFP). TFP was computed using a Cobb-Douglas production function

$$
y_{t}=e^{s t} k_{t}^{\alpha}\left(x_{t} l_{t}\right)^{1-\alpha}
$$

where the lowercase variables stand for per capita, $k$ is capital and $l$ hours worked. Non-detrended TFP is given by $e^{s_{t}} x_{t}^{1-\alpha}$. Labour-augmenting technological progress is represented by $x$, whose growth at the rate $g$ gives the deterministic trend of the economy. $e^{s}$ is the stochastic component of TFP, i.e. its deviations from trend, and therefore what remains after detrending TFP. As shown in Figure 9, TFP was on trend until 1931, but fell progressively thereafter up to $10 \%$ below trend in 1934, with no apparent recovery to trend before the outbreak of the war. An interesting feature of TFP's behaviour in Belgium is that, though it never recovered its trend level during 
the late 1930s, it got near its trend growth rate from 1936 onwards. This is evident from a glance at Figure 10, where I have graphed the deterministic trend of TFP together with its observed value, both standardised to 100 in 1929.

The next step is to assess whether, in a RBC model with exogenous TFP shocks, the observed behaviour of TFP is sufficient to account for output movements in Belgium during the Great Depression. This task is undertaken in the next session.

\section{A Baseline RBC Model of the Belgian Great Depression}

\subsection{The Model}

I assume perfect competition and complete markets. I consider a closed economy populated by an infinitely long-living representative household, which solves the maximization problem:

$$
\max _{\left\{c_{t}, l_{t}, k_{t+1}\right\}_{t=0}^{\infty}} E_{t} \sum_{t=0}^{\infty} \beta^{t}\left[\ln \left(c_{t}\right)+\phi \ln \left(1-l_{t}\right)\right],
$$

under the constraints:

$$
\begin{gathered}
c_{t}+k_{t+1} \leq(1-\delta) k_{t}+y_{t}, \\
y_{t}=e^{s_{t}} k_{t}^{\alpha}\left(x_{t} l_{t}\right)^{1-\alpha}, \\
s_{t}=\rho s_{t-1}+v_{t}, \\
x_{t}=\gamma^{t} x_{0} \\
0<\rho<1, \\
k_{0}=\text { given }, \\
s_{0}=\text { given } .
\end{gathered}
$$

In this model, I have assumed a log-log, time separable utility function. The parameter $\beta$ is the household's discount rate. $\phi$ is the relative weight that leisure holds in the utility function and $\delta$ is the capital depreciation rate due to technical obsolescence and physical disruption. I have assumed that detrended TFP, $s_{t}$, follows an $\operatorname{AR}(1)$ process with $\rho$ being its $\operatorname{AR}(1)$ coefficient, and $v_{t}$ being a zero-mean i.i.d. innovation.

The first order conditions of this problem are given by 


$$
\begin{gathered}
\gamma \frac{1}{\tilde{c}_{t}}=E_{t}\left[\beta \frac{1}{\tilde{c}_{t+1}}\left(1-\delta+\alpha e^{s_{t+1}}\left(\frac{\tilde{k}_{t+1}}{l_{t+1}}\right)^{\alpha-1}\right)\right], \\
\gamma \tilde{k}_{t+1}=(1-\delta) \tilde{k}_{t}+e^{s_{t}} \tilde{k}_{t}^{\alpha} l_{t}^{1-\alpha}-\tilde{c}_{t}
\end{gathered}
$$

and

$$
\frac{\phi}{1-l_{t}}=\frac{1}{\tilde{c}_{t}} e^{s_{t}}(1-\alpha)\left(\frac{\tilde{k}_{t}}{l_{t}}\right)^{\alpha},
$$

plus a transversality condition, where $\tilde{x}$ means detrended $x$.

In such an economy there exist a stationary state growth path for all the detrended variables.

\subsection{Calibration}

In order to simulate the model economy, I need to calibrate the parameters of the model. Table 1 illustrates my choices.

\begin{tabular}{rr}
\hline$\beta$ & 0.96 \\
$\gamma$ & 1.03 \\
$\delta$ & 0.1 \\
$\alpha$ & 0.33 \\
$\phi$ & 1.78 \\
$\rho$ & 0.99 \\
\hline
\end{tabular}

Table 1: Calibration of the parameters

The unit period is the year. The parameters $\beta, \delta$ and $\alpha$ are fixed accordingly, as in Cole and Ohanian (1999). The deterministic growth rate of the economy is derived as explained in Section 4.1 above. The parameter $\phi$ is calibrated so that the hours worked $(l)$ are $1 / 3$ in the steady state. The autocorrelation parameter $\rho$ is estimated by regressing the logarithm of the detrended TFP (i.e. $s_{t}$ in the model) as an autoregressive process of order 1 .

\subsection{Simulation}

I assume the model economy to be in a steady state in $1929 .{ }^{5}$ I fed in the residuals from regressing the logarithm of detrended TFP as AR(1) to

\footnotetext{
${ }^{5}$ Note that the assumption that the economy was in a steady state in 1929 may be plausible, but it is not a priori justifiable.
} 
represent the unexpected shock $v_{t}$. Figures 11 and 12 present the dynamic response of the model to the shock.

The model reproduces about 35\% of the 1929-1934 output drop. It shows no signs of recovery after 1934, a feature in full accordance with the data.

The model performs similarly in accounting for consumption. Some $31 \%$ of its 1929-1934 drop is accounted for. From 1934 onwards consumption stays constant in the model, while it kept on decreasing slightly in the data. As a result, in 1938 the model accounts for just $28 \%$ of the consumption drop.

As for investments, (Figure 12), the model is able to replicate $37 \%$ of their 1929-1934 drop. Things worsen when we consider 1938, with the model accounting for a mere $14 \%$ of the behaviour of investments. This is because in the model investments recover after 1934, although not to the trend level, whereas in fact they dropped even more.

As far as hours worked are concerned, the model accounts for a slim $5 \%$ of their 1929-1934 drop. In 1938, it accounts for virtually none of their behaviour. ${ }^{6}$

\subsection{Comments on the Results}

According to the exercise described above, TFP shock is not a likely culprit for explaining the Great Depression in Belgium. First, there is a timing problem. The detrended data in Figure 9 shows that the economy entered the Great Depression in 1930, one year later than elsewhere. However, we can see in the same graph that TFP stayed at trend - and even slightly above trend - until 1931. It dropped $10 \%$ below trend between 1932-1934, to stay basically constant thereafter.

This translates to a problem of both direction and dimension of the TFP movements. In my simulation, as a consequence of the TFP behaviour, output, consumption and investments increase until 1931, to decrease only later on, a pattern at variance with the data.

A third problem relates to the quantitative side. The simulation's results

\footnotetext{
${ }^{6}$ Assuming that the utility function is logarithmic in leisure is tantamount to assuming that the intertemporal elasticity of substitution of labour supply $\sigma$ is equal to 1 , in a CES specification such as

$$
U\left(c_{t}, l_{t}\right)=\ln c_{t}+\phi \frac{\left(1-l_{t}\right)^{1-\frac{1}{\sigma}}}{1-\frac{1}{\sigma}} .
$$

As typical estimates for $\sigma$ range around $[0.4,1]$ (Cahuc and Zylberberg (2004)), such an assumption is fair to the RBC transmission mechanism, in that, if anything, it overestimates the transmission of the TFP shock. For the sake of completeness, I ran two further simulations, one with $\sigma=0.4$ and the other with $\sigma=1.25$. The latter value was chosen to be the threshold superior limit, as in Merz (1995). The results did not change appreciably.
} 
are rather poor, with the model only able to account for a small percentage of the variables' behaviour. This is particularly true as far as labour input is concerned.

These results suggest two directions for further enquiries. The first has to do with the dynamics of investments. A better account of the big drop we observe in detrended investments would mark an appreciable improvement over the TFP-driven explanation provided here above. This is particularly true for the years 1934-38, where the discrepancy between the RBC model and the data is large.

The second line of research concerns to the behaviour of the labour input. As TFP was above trend in 1930-31, and given the time-to-build assumption that fixes capital in any period $t$, simple growth accounting suggests that the behaviour of hours worked is crucial for explaining the onset of the Depression.

The next two sections are devoted to the task of identifying and modelling the additional shocks that may lie behind the behaviour of the production factors.

\section{$6 \quad$ War Expectations and Investments}

A striking aspect of the Belgian Great Depression is the dimension of the drop in detrended investments. A possible explanation of such a drop can be that sometime in the 1930s agents started to expect a war, and so began to reduce their capital accumulation. Baudhuin (1961) argues that when Germany remilitarized the Rhein region in 1936, worries about a possible war started to circulate. These worries became fully fledged after the annexion of Austria in 1938.

To see whether war expectations may play a role in explaining investment dynamics, I simulated the same basic RBC model as in section 5.1, with two differences. First, I assumed zero unexpected TFP shock, in order to isolate the effect of war expectations. Second I imposed an expected exogenous variation on the rate of capital depreciation $\delta$ for the 1940-45 years. The idea was to translate the anticipated physical destruction of the stock of capital into a variation of the depreciation rate. I chose two benchmark values for $\delta$ : 0.1387, which I have computed in deriving the capital series to account for the destruction induced by WWI (see Appendix); and a maximum value of 0.5 , which means that half of the capital stock is destroyed each year. The results are shown in figures 13 and 14.

If, in 1929, agents had perfectly foreseen WWII, expecting a degree of destruction in the stock of capital equal to that experienced in the "Great 
War" (as WWI was known), then the simulated model can account for about $4 \%$ of the investment drop in 1938. Output decrease in the model accounts for $8 \%$ of the actual drop in output in 1938. Consumption in the model stays slightly above the trend, thus not accounting at all for the observed behaviour of the data. The same is true for hours worked, but for the fact that this variable shows a slightly decreasing trend, accounting for about $1.5 \%$ of the observed slump in actual hours worked in 1938.

If the maximum value $\delta=0.5$ is chosen for simulation, than the model can account for a greater proportion of the fall in output, investment and hours worked in 1938 (37.5\%, 74\% and 53\% respectively). Consumption shows a counterfactual behaviour, increasing steadily up to $2 \%$ above trend.

This exercise shows that in this type of model, war expectations can play a role in explaining investment dynamics only if the expected disruptions induced by the war are very large. In the model, this translates into an expected loss of capital stock that is much bigger than that caused by WWI. Historically, this seems implausible. People could well have being judging a war to be increasingly probable, starting from, say, 1936. Yet it is highly improbable that they were expecting something as ruinous as being four or five times the scale of WWI. Moreover, if introducing "realistic" war expectations into the model slightly improves on the results based on TFP shocks for inputs and output, the model results for consumption deteriorate.

All in all, war expectations could be a useful refinement of the model, but they do not seem to be decisive in accounting for the Belgian Great Depression.

\section{$7 \quad$ Money and Sticky Wages}

Results with the benchmark RBC model suggest that an explanation of the onset of the Great Depression in Belgium must rely mainly on explaining the behaviour of the labour input. In fact, detrended output began to decrease in 1930, whereas TFP stayed above the trend until 1931, to start decreasing only later on.

As real wages were actually increasing up to 1932, the data seem to suggest that high real wages might be a causal factor in the behaviour of hours worked. At the same time, nominal wages decreased sharply between 1930 and 1935. This suggests that nominal variables must be taken into account as well. As price level dropped by $25 \%$ in the same period (Figure 7 ), one possible explanation is that nominal wages staggered, so that prices decreased more than nominal wages, resulting in increased real wages and, consequently, in unemployment. This is the position held, for instance, by 
Goossens (1988). It would imply the existence in the data of a downward sloping Phillips curve, i.e. a negative relation between the rate of variation of monetary wages (or inflation) and the unemployment rate. Cassiers (1989b) argues such a relation is indeed evident for Belgium in the years 1929-1932. Figure 15 shows a standard Phillips curve for the 1921-1938 period. The figure suggests the existence of an inverse relation between the two variables. ${ }^{7}$

If, according to this evidence, sticky wages are a plausible propagation mechanism for the Great Depression in Belgium, we still have to identify a source for deflation. According to historians of the period, a major role in this respect was played by exchange-rate problems in the context of the gold-standard regime. When, in 1931, the United Kingdom devalued the pound, so the story goes, the Belgian franc got overvalued, forcing domestic authorities to deflate the economy in order to keep market quotas intact for the export sector. In that context of exchange-rate pegging, money supply became quasi-endogenous, as it adjusted to the trade balance following predetermined rules. This means that the Belgian Central Bank had to move the discount rate and the monetary base in order to keep the value of the Belgian franc stable, whenever the trade balance showed a surplus or a deficit. In the event of a unilateral devaluation by an important commercial partner, the monetary authority had to sterilise the subsequent gold outflow, and to deflate internal prices in order to keep competitiveness on foreign markets. This direct link between the exchange rate and the money supply in a goldstandard regime suggests that, in the task of modelling the nominal shock we want to hold as responsible for the onset of the Belgian Great Depression, we can use exogenous monetary shocks as a proxy for exchange-rate variations. The use of this shortcut is supported by the data on nominal money. There was indeed a monetary contraction starting from 1931 (see Figure 7).

In the light of these arguments, I shall investigate the role of nominal shocks and sticky wages, in a closed-economy monetary model with contractstaggering. For all its being but a rough shortcut, this trick will enable me to produce a first assessment of the role of sticky wages and nominal shocks, while retaining a simple model. Moreover the use of a closed-economy model makes the results directly comparable with those of Section 5 .

\footnotetext{
${ }^{7}$ The same exercise is repeated in Figure 16, substituting the inflation rate for the nominal wage variation rate. Though the scatter again suggests a negative relation between the two variables, the evidence here is less conclusive than in the previous graph. This can be interpreted as evidence that monetary wages and CPI followed different patterns, as the latter could have been more influenced by exchange rate troubles.
} 


\subsection{The Model}

The model of Section 5.1 is modified to introduce sticky wages and monetary shocks. I have drawn inspiration from Bordo, Erceg, and Evans (2000), who carried out a similar analysis for the United States.

First, I assumed fixed labour supply. Second, I postulated a nominal wage rigidity à la Taylor (1980). ${ }^{8}$ In this setting, workers are divided into two cohorts, each fixing its nominal contract-wage for two years. The contract scheme is such that, say, cohort one fixes its contract in $t$ for periods $t$ and $t+1$, while cohort two fixes its contract in $t+1$ for periods $t+1$ and $t+2$. Then cohort one fixes its contract in period $t+2$ for periods $t+2$ and $t+3$, and so on and so forth. Thus in each period $t$, there will be two different contracts, one for the cohort which fixed it in period $t-1$ and one for the cohort which fixed it in period $t$. Calling $\chi_{t}$ the contract set in period $t$, the average nominal wage in period $t$ will be

$$
W_{t}=\chi_{t}^{\frac{1}{2}} \chi_{t-1}^{\frac{1}{2}}
$$

Each contract is fixed according to the rule

$$
\ln \left(\chi_{t}\right)=\frac{1}{2}\left[\ln \left(W_{t}\right)+E_{t}\left(\ln \left(W_{t+1}\right)\right)\right]+\frac{\xi}{2}\left[\ln \left(\frac{l_{t}}{\bar{l}}\right)+\ln \left(\frac{l_{t+1}}{\bar{l}}\right)\right] .
$$

The meaning of Equation 7 is that, when negotiating contracts, agents set them at the geometric mean of the current average wage and the expected future average wage, as they know they will not be able to modify the contract in the next period. The last term on the right hand side makes contracts dependent on general labour market conditions: the contract will be positively (or negatively) influenced by the hours worked being higher (or lower) than a benchmark level $\bar{l}$, which is the steady-state level, when wages are perfectly flexible and the labour supply is endogenous.

By substituting Equation 7 in Equation 6, and assuming perfect foresight, we get

$$
\ln \left(W_{t}\right)=\frac{1}{2} \ln \left(W_{t+1}\right)+\frac{1}{2} \ln \left(W_{t-1}\right)+\frac{\xi}{2}\left[2 \ln \left(\frac{l_{t}}{\bar{l}}\right)+\ln \left(\frac{l_{t+1}}{\bar{l}}\right)+\ln \left(\frac{l_{t-1}}{\bar{l}}\right)\right],
$$

which gives the average wage at time $t$ as a function of past and expected future values of the average wage, and of past, present and future conditions on the labour market.

\footnotetext{
${ }^{8}$ I use Taylor-staggering, as Bordo, Erceg, and Evans (2000) do, because it is the simplest way to make my point on the possible role of sticky wages, in the presence of monetary shocks. Nonetheless, I admit that a proper micro-foundation for wage stickiness would make the model more robust.
} 
Finally, I assume that agents get utility from holding real money balances. The timing assumption is that agents get their utility from the real quantity of money $m_{t}=\frac{M_{t}}{P_{t}}$ that remains at the end of period $t$, after purchasing consumption goods. ${ }^{9}$

Therefore the problem of the representative household will be

$$
\max _{\left\{c t, m_{t}, k_{t+1}\right\}_{t=0}^{\infty}} E_{t} \sum_{t=0}^{\infty} \beta^{t}\left[\mu \ln \left(c_{t}\right)+(1-\mu) \ln \left(m_{t}\right)\right],
$$

under the constraints:

$$
\begin{gathered}
c_{t}+k_{t+1}+m_{t} \leq(1-\delta) k_{t}+y_{t}+\frac{m_{t-1}}{1+\pi_{t}}+\tau, \\
y_{t}=e^{s t} k_{t}^{\alpha}\left(x_{t} l_{t}\right)^{1-\alpha}, \\
s_{t}=\rho s_{t-1}+v_{t}, \\
x_{t}=\gamma^{t} x_{0}, \\
0<\rho<1, \\
\zeta_{t}=\ln \left(M_{t}\right)-\ln \left(M_{t-1}\right), \\
\zeta_{t}-\hat{\zeta}=\theta_{t} \\
\theta_{t}=\eta \theta_{t-1}+\nu_{t}, \\
\pi_{t} \equiv \frac{P_{t}-P_{t-1}}{P_{t-1}} \\
k_{0}=\text { given, } \\
s_{0}=\text { given, } \\
\theta_{0}=\text { given. }
\end{gathered}
$$

Here $v_{t}$ and $\nu_{t}$ are zero-mean i.i.d. innovations, $\tau_{t}$ is a lump-sum nominal transfer paid by the government when it issues money, (which in equilibrium must be equal to the seignorage, $m_{t}-\frac{m_{t-1}}{\left(1+\pi_{t}\right)}$, in order to balance the government budget), and $\zeta_{t}$ is the growth rate of per-capita money stock, which is assumed to follow an $\mathrm{AR}(1)$ process, with $\hat{\zeta}$ and $\eta$ as given parameters. I assume complete markets, perfect competition in the goods market and perfect foresight.

Computing the first order conditions for this problem, and detrending all the variables, the relevant equations for characterising a solution are

\footnotetext{
${ }^{9}$ See Carlstrom and Fuerst (2001) for alternative timing assumptions.
} 


$$
\begin{gathered}
\gamma \frac{1}{\tilde{c}_{t}}=E_{t}\left[\beta \frac{1}{\tilde{c}_{t+1}}\left(1-\delta+\alpha e^{s_{t+1}}\left(\frac{\tilde{k}_{t+1}}{l_{t+1}}\right)^{\alpha-1}\right)\right] ; \\
\gamma \tilde{k}_{t+1}=(1-\delta) \tilde{k}_{t}+e^{s_{t}} \tilde{k}_{t}^{\alpha} l_{t}^{1-\alpha}-\tilde{c}_{t}-\tilde{m}_{t}+\frac{\tilde{m}_{t-1}}{\gamma\left(1+\pi_{t}\right)}+\tilde{\tau} ; \\
\frac{1-\mu}{\tilde{m}_{t}}=\frac{\mu}{\tilde{c}_{t}} \frac{i_{t}}{1+i_{t}} ; \\
1-\delta+\alpha e^{s_{t+1}} \tilde{k}_{t+1}^{\alpha-1} l_{t+1}^{1-\alpha}=\frac{1+i_{t}}{1+\pi_{t+1}} ; \\
\ln \left(\tilde{w}_{t}\right)=\frac{1}{2} \ln \left(\tilde{w}_{t+1}\right)+\frac{1}{2} \ln \left(1+\pi_{t+1}\right)+\frac{1}{2} \ln \left(\tilde{w}_{t-1}\right)-\frac{1}{2} \ln \left(1+\pi_{t}\right)+ \\
+\frac{\xi}{2}\left[2 \ln \left(\frac{l_{t}}{\bar{l}}\right)+\ln \left(\frac{l_{t+1}}{\bar{l}}\right)+\ln \left(\frac{l_{t-1}}{\bar{l}}\right)\right] \\
\tilde{w}_{t}=(1-\alpha) e^{s} \tilde{k}_{t}^{\alpha} l_{t}^{-\alpha}
\end{gathered}
$$

plus a transversality condition.

The first two equations are respectively the usual Euler condition and the resource constraint. Equation 12 is the money demand, which turns out to be a function of current consumption and the nominal interest rate $i_{t}{ }^{10}$ Equation 13 is the Fisher equation, stating that nominal interest rates must be equal to the real interest rate, i.e. the marginal product of capital, plus the expected inflation rate. ${ }^{11}$ Equation 14 gives the rule of formation of detrended real wages $\tilde{w}$. It comes from detrending Equation 8. Its role in the model is to determine hours worked, via the labour demand (Equation $15)$.

\subsection{Calibration}

Table 2 shows the parametrisation of the model. The unit period is the year. The parameters $\alpha, \beta, \gamma, \delta$ and $\rho$ are the same as in Section 5.2.

\footnotetext{
${ }^{10} \mathrm{~A}$ clarification on timing. I define $i_{t}$ as the nominal interest rate paid in period $t+1$ to the owners of bonds issued in period $t$.

${ }^{11}$ The Fisher equation reported in the text can be formally derived by adding bonds as a choice variable in the model. Given that bonds play no other role in my model, I have dropped them, and just added the Fisher equation as an exogenous definition of the nominal interest rate.
} 


\begin{tabular}{rr}
\hline$\beta$ & 0.96 \\
$\gamma$ & 1.03 \\
$\delta$ & 0.1 \\
$\alpha$ & 0.33 \\
$\xi$ & 0.0148 \\
$\rho$ & 0.99 \\
$\eta$ & 0.14 \\
$\mu$ & 0.5 \\
$\hat{\zeta}$ & 0.05 \\
\hline
\end{tabular}

Table 2: Calibration of parameters

The parameter $\hat{\zeta}$ is the average annual growth rate of nominal money supply. The typical value for this variable is 0.05 (Walsh (2003)). To check its adequacy for Belgium in the period under examination, I estimated $\hat{\zeta}$ by running the following $\mathrm{AR}(1)$ on the available data for the interwar period:

$$
\zeta_{t}=(1-\eta) \hat{\zeta}+\eta \zeta_{t-1}+\nu_{t}
$$

The result is $\hat{\zeta}=0.047 .^{12}$

The parameter $\eta$ is estimated by regressing $\theta_{t}$ as an $\operatorname{AR}(1)$ without drift.

The relative weight of consumption and real balances in the utility function plays no role in the dynamics, so there is no need to calibrate it. I chose $\mu=0.5$.

The trickiest parameter to calibrate is $\xi$, which gives the elasticity of nominal contracts to labour market conditions. A high value of $\xi$ means a relatively lower degree of wage rigidity: nominal contracts react faster to hours worked being above or below the steady state value. Vice versa, a low value of $\xi$ implies a higher degree of rigidity. Estimates on quarterly U.S. data by Bordo, Erceg, and Evans (2000) gave $\xi=0.0037$. This value was chosen by the authors as the one that minimised the average square difference between the observed and simulated real-wage series. Their estimation was run on the period 1929:4-1933:2. Given that I have yearly data, I chose the benchmark $\xi$ to be four times their estimation. Then, I ran a sensitivity analysis as follows. I compared the growth rates of the series implied by the model with that of the data for threshold values of $\xi$. These values were chosen to be two times, four times, a quarter and a eighth the benchmark

\footnotetext{
${ }^{12}$ Bordo, Erceg, and Evans (2000) ran a similar regression on quarterly U.S. data, limited to the period 1922:2-1928:4. Adjusted on a yearly basis, their estimations gave a value of 0.02 for $\hat{\zeta}$.
} 
value. The model was simulated after feeding in the series of estimated $\nu_{t}$. This is the series of residuals from regressing $\theta_{t}$, (the deviation of the growth rate of nominal money supply from its long-run average value), as an $\mathrm{AR}(1)$. It stands for unexpected monetary shock, and it is plotted in Figure 17. Productivity shocks were set to zero. ${ }^{13}$

Figure 18 shows the results of this sensitivity exercise. It shows that the choice of $\xi$ (xi) within the range of values considered does not affect the results in any important way. The figure also shows that my benchmark value of 0.0148 is a conservative one, with respect to the observed wage rigidity. This guarantees that, if anything, the approximation will run against the objective of this model, which is to account for the Great Depression in Belgium by means of wage rigidities and monetary shocks.

\subsection{Simulation}

The model economy is assumed to be in steady state in 1929. The monetary shock series were fed in as explained above, and TFP shocks were set to zero. Figures 19, 20 and 21 show the dynamic response of the model to the unexpected monetary shock, and compare it with the dynamics of the data.

The model reproduces about $115 \%$ of the 1929-1934 drop in output (Figure 19). Simulated output returns nearly to trend in 1935-36, to witness a $10 \%$ further drop below the trend level in 1937. However, in the detrended data output stagnated around 20\% below trend in 1935-1937.

The model predicts slightly more than 100\% of the 1929-1934 drop in consumption. As far the 1935-1937 period is concerned, the model differs from the data in much the same way as output does.

The drop in investments is overestimated by the model, which accounts for about $110 \%$ of the actual drop between 1929 and 1934 (Figure 20). Again, the model predicts a recovery after 1935 which is not in the data.

The same pattern is evident as far as hours worked is concerned. At the trough of the depression, the model's hours are $35 \%$ below trend, whereas in the data they were "only" $21 \%$ below trend. The model shows a recovery in 1935-1936 which is not in the data. However, it matches the 1937 value.

Figure 21 show that the model fits the behaviour of real cash balances reasonably well, but it has some problems as far as the inflation rate is concerned. In particular, the model dramatically overestimates the 1935

\footnotetext{
${ }^{13}$ I shut down productivity shocks because, as the data suggest that nominal shocks might have been important, I wanted to isolate the effect of purely nominal shocks first, without confusing them with other sources of fluctuations. Section 7.6 takes productivity shocks into account, and shows that nominal shocks were indeed crucial.
} 
value of infltion. ${ }^{14}$

\subsection{Comments on the Results}

This exercise shows that monetary shocks with nominal sticky wages provides a step in the right direction for an explanation of the slump in the early 1930s. This is in line with the suggestions put forward by historians.

The improvement on the simpler RBC model of Section 5 is appreciable, especially as concerns the behaviour of investments and hours worked. However, there are still three respects in which the model is not satisfactory. First, the model predicts an initial increase of detrended output in 1930, which is at variance with the data. Second, it overestimates output and investment dynamics in 1929-1934, meaning that either the propagation mechanism is too strong, or the impulse mechanism was mismeasured, i.e. the monetary shock that was fed in a was too strong.

The third unsatisfactory aspect of the model is that it fails to explain the 1935-1937 absence of recovery. A first interpretation of this finding is that the monetary expansion due to the 1935 devaluation was mismeasured. The sudden upsurge in 1935 estimated $\nu_{t}$ in Figure 17 and the abnormal model inflation dynamics in Figure 21, both suggest this might be the case. Another possible interpretation is that the model assumes a symmetric wage staggering. That is, wages are assumed to be be as sticky downwards as they are upwards. This implies that the big monetary expansion led by the devaluation of 1935 causes inflation to increase in the model, thereby dragging real wages downwards. In fact, what we observe in the data (Figure 18) is almost the contrary: after 1935 detrended real wages suddenly increased further above the trend.

\subsection{Asymmetric Wage Rigidity}

As suggested above, a possible interpretation of the inability of the stickywages model to account for the 1935-1937 absence of recovery is that we may need a model in which nominal wage rigidity is asymmetric, with wages being rigid downwards, but flexible upwards. This interpretation may find support

\footnotetext{
${ }^{14}$ For the sake of comparison, the price levels in Figure 21 are built upon the inflation rate, using the formula

$$
P_{t+n}=P_{t} \prod_{j=0}^{n}\left(1+\pi_{t+n-j}\right), \text { for } \mathrm{n}=[1,2, \ldots],
$$

where $P_{t}=100$ and $t=1929$.
} 
from historical evidence suggesting that in 1936 a wave of strikes spreading from France shook the country, with an appreciable, if not enduring, effect on increasing nominal wages (Baudhuin (1961)).

To verify such a hypothesis, I carried out the following experiment. The 1929-1937 period was split into two subperiods. In the first, covering the years 1929-1934, I used the same model as in the previous section, with Taylor wage-staggering and monetary shocks. In the second period, covering 19351937, I assumed a competitive labour market, with endogenous labour supply and monetary shocks. The leisure choice appears in the utility function in log-additive terms. The results of a model with asymmetric wage rigidity (amr) are shown in figures 22, 23, 24 and 25.

This exercise does not confirm the hypothesis that asymmetric wage rigidity could have played a role. The dynamics of the model with competitive wages since 1935 are only slightly less accentuated than that with Taylor staggering. The reason for the qualitative behaviour of the model economy is that by construction the model economy is always on a saddle-path converging to the steady state. This means that, if the economy is far below the steady state, mechanisms exist for convergence to be achieved in the absence of shocks. In particular, the starting point in 1934 was characterized by capital, output and consumption below, and real wages above, the steady state. This means that investments must "overshoot" to build up new capital stock, while workers will substitute relatively expensive leisure for consumption. ${ }^{15}$

In conclusion, it seems that an additional negative shock is required to account for the absence of recovery in 1935-37.

\subsection{TFP Shocks and Sticky Wages}

This section serves the purpose of showing how the monetary model with sticky wages would fare, were TFP shocks the only impulse mechanism at work during the Belgian Great Depression. The contribution of this exercise is to examine whether the Great Depression was really a monetary phenomenon, or whether, if nominal wage stickiness is assumed, TFP shocks and monetary shocks have comparable data-mimicking abilities.

\footnotetext{
${ }^{15}$ Simulations with the same model and zero monetary shocks produce identical results, meaning that, in the model economy with competitive wages, positive nominal shocks play no role in the recovery. On the contrary, if the monetary shock is shut down for the same period in the Taylor scenario, the recovery is much smoother. The reason is that it takes time for wages to adjust, while nominal disturbances still have a (tiny) autoregressive component. As expected, if we assume that the economy was in steady state in 1934, then the big positive monetary shock of 1935 has large real effects in the model with Taylor staggering.
} 
In order to carry out this exercise, monetary shocks were set to zero and the TFP shocks were fed in as in Section 5. The results are shown in Figures 26, 27 and 28.

As can be easily seen from the graphs, TFP shocks perform worse than monetary shocks in accounting for the onset of the Great Depression. Indeed, the presence of Taylor staggering in nominal wages does not produce appreciable improvements on the transmission mechanism of TFP shocks, with respect to the baseline model of Section 5. Like that model, TFP shocks performs better than the monetary model in accounting for the 1935-37 data. As expected, the model produces counterfactual inflation dynamics, and a poorer fit to the real cash balances. However, such a feature is meaningless, as these variables are strictly dependent on the behaviour of the money supply. Given that the growth rate of money supply $\zeta$ is constrained to be equal to $\hat{\zeta}$ by setting $\theta=0$, it is no surprise that the fit is worsened.

My conclusion from this exercise is that wage stickiness may be an important transmission mechanism in a model with monetary shocks, but plays no appreciable role in one with TFP shocks.

\section{A Small Open Economy RBC Model}

So far, the argument has run within a closed-economy set up.

For all its being in line with the literature on RBC models of the Great Depression, such a perspective still contrasts with the common wisdom among historians, who maintain that the Belgian Great Depression is better understood once the small open economy dimension is taken into account (Cassiers (1989a)). A robustness check seems therefore in order. This section illustrates how the results are likely to be modified once we extend the analysis to encompass the open-economy dimension. As a complete analysis of the open-economy scenario falls beyond the limits of the present work, I shall limit myself to a very basic RBC model, ignoring the complications coming from money and price stickiness, and from exchange rates as well.

\subsection{The Model}

The model draws on Mendoza (1991), and is a modified version of that of Section 5. It is assumed that the economy can exchange assets with the rest of the world. These assets pay a constant real interest rate $r^{*}$. The small-openeconomy assumption implies that the domestic economy cannot influence the value of $r^{*}$. Therefore, in a deterministic set-up a no-arbitrage condition must exist: ex ante, the domestic real interest rate, which is equal to the 
marginal product of capital, ought in turn to be equal to $r^{*}$. The obvious implication is that, if an ex ante discrepancy between $r$ and $r^{*}$ is observed, capital and hours worked have to adjust until the no-arbitrage condition is again satisfied. A crucial assumption is that foreigners cannot own domestic physical capital. Labour is immobile, and markets are incomplete, in the sense that no contracts contingent on the realisation of the shocks exist. Of course, the presence of lending and borrowing on the world market provides agents with some insurance.

Let $b_{t}$ be the value of per capita net foreign assets held by the representative household at the end of period $t-1$. Following Obstfeld and Rogoff (1996), I define the current account balance in period $t, C A_{t}$, as

$$
C A_{t} \equiv b_{t+1}-b_{t}
$$

Therefore, in this model the current account is the variation of the net claims of a country over the rest of the world. ${ }^{16}$

The presence of assets adds a variable to the optimisation problem faced by our representative household: how many assets to hold at the end of the period, given its initial endowment.

The model of section 5 then becomes:

$$
\max _{\left\{c_{t}, l_{t}, k_{t+1}, b_{t+1}\right\}_{t=0}^{\infty}} E_{t} \sum_{t=0}^{\infty} \beta^{t}\left[\ln \left(c_{t}\right)+\phi \ln \left(1-l_{t}\right)\right],
$$

under the constraints:

$$
\begin{aligned}
c_{t}+k_{t+1}+b_{t+1} & \leq(1-\delta) k_{t}+y_{t}+\left(1+r^{*}\right) b_{t}, \\
y_{t} & =e^{s_{t}} k_{t}^{\alpha}\left(x_{t} l_{t}\right)^{1-\alpha} \\
s_{t} & =\rho s_{t-1}+v_{t}
\end{aligned}
$$

\footnotetext{
${ }^{16}$ This concept corresponds to the traditional concept of current account balance as net exports. To see that, decompose the budget constraint

$$
c_{t}+k_{t+1}+b_{t+1}=(1-\delta) k_{t}+y_{t}+\left(1+r^{*}\right) b_{t}
$$

into

$$
\begin{gathered}
k_{t+1}=(1-\delta) k_{t}+i_{t} \\
i_{t}=y_{t}-c_{t}+r^{*} b_{t}-C A_{t} .
\end{gathered}
$$

As the first three terms on the right-hand side corresponds to national savings, and remembering from national accounts that $I-S=M-X$, where $M$ stands for imports and $X$ for exports, it follows that $C A=X-M$, where everything is expressed in per capita terms.
} 


$$
\begin{gathered}
x_{t}=\gamma^{t} x_{0} \\
0<\rho<1, \\
k_{0}=\text { given, } \\
b_{0}=\text { given, } \\
s_{0}=\text { given } .
\end{gathered}
$$

I assume perfect foresight. Computing the first order conditions of this problem, and detrending all the variable, the relevant equations for characterising a solution are:

$$
\begin{gathered}
\frac{1}{\tilde{c}_{t}}=\frac{\beta}{\gamma}\left(1+r^{*}\right) \frac{1}{\tilde{c}_{t+1}} \\
1-\delta+\alpha e^{s_{t+1}}\left(\frac{\tilde{k}_{t+1}}{l_{t+1}}\right)^{\alpha-1}=1+r^{*} \\
\gamma\left(\tilde{k}_{t+1}+\tilde{b}_{t+1}\right)=\left(1+r^{*}\right) \tilde{b}_{t}+(1-\delta) \tilde{k}_{t}+e^{s_{t}} \tilde{k}_{t}^{\alpha} l_{t}^{1-\alpha}-\tilde{c}_{t} \\
\frac{\phi}{1-l_{t}}=\frac{1}{\tilde{c}_{t}} e^{s_{t}}(1-\alpha)\left(\frac{\tilde{k}_{t}}{l_{t}}\right)^{\alpha} ;
\end{gathered}
$$

plus transversality conditions. What is new here, with respect to the previous model, is the no-arbitrage condition in Equation 18, whereas Equations 17 and 19 give the open-economy version of the Euler equation and the budget constraint respectively.

As is well known in the literature, the steady state of this class of openeconomy models turns out to be consistent with any initial level of net assets (Correia, Neves, and Rebelo (1995), Kim and Kose (2003)). This multipleequilibria feature introduces a stationarity problem in the model: at steady state, a country with higher net assets holdings will be able to afford higher trade deficits, and therefore higher consumption levels. As a consequence, any shock, even if trend-stationary, will have permanent effects on assets and therefore on consumption. This introduces a random-walk component in the model.

Many ways exist to solve this problem (Schmitt-Grohé and Uribe (2003)). I chose to impose a risk premium on the real interest rate paid or received by the domestic economy. The idea is that the lower the net asset holding of the country, or, when $b$ is negative, the higher its foreign debt, the higher the 
interest rate it has to pay to borrow more will be. So, in the model above, we can substitute $r^{*}$ with

$$
r_{t}=r^{*}+\psi\left(e^{-b_{t}}-1\right)
$$

This trick stationarises the model, as the steady state level of $b$ is now determined by the Euler equation, and turns out to be a function of $r^{*}$ and $\psi$ only.

\subsection{Calibration and Simulation}

The model is calibrated as in Section 5. The parameter $\psi$ is calibrated so that the model matches the standard deviation of $\frac{C A}{y}$ during the 1930s. The steady-state world interest rate is given at $r^{*}=\frac{\gamma}{\beta}-1$. I assume the economy to be in steady state in 1929. In the model, the steady-state value of current account is assumed to be 0 , as are the initial and steady-state values of net foreign assets. I feed in TFP shocks as in Section $5 .{ }^{17}$ The results are shown in Figures 30, 31 and 32.

\begin{tabular}{rr}
\hline$\beta$ & 0.96 \\
$\gamma$ & 1.03 \\
$\delta$ & 0.1 \\
$\alpha$ & 0.33 \\
$\phi$ & 1.78 \\
$\rho$ & 0.99 \\
$\psi$ & 0.465 \\
$r^{*}$ & $\frac{\gamma}{\beta}-1$ \\
\hline
\end{tabular}

Table 3: Calibration of parameters

As is evident from the graphs, no appreciable improvements on the closedeconomy RBC model of Section 5 are observed. The two models hold the same explanatory power for output, consumption and labour dynamics. The open-economy model fares slightly better in accounting for the investment drop, at the price of having too volatile investment behaviour after 1934 . Such a feature is in full accordance with standard results in the literature: small-open-economy RBC models tends to accentuate investment volatility

\footnotetext{
${ }^{17}$ It is worth noticing that in an open-economy model context, TFP shocks encompass terms of trade variations, as aptly argued by Mendoza (1991).
} 
(Mendoza (1991)). ${ }^{18}$

As to the behaviour of the current account, the model performs rather poorly. It predicts countercyclical behaviour of the current account over output, which is evidently at variance with the data. As this may be due to the assumption of a balanced steady-state current account, it can be useful to compare trends instead of levels. So, in Figure 32, I have included an additional line, the shifted data line, normalised so that the value of the current account over output is zero in 1929. In comparing it with the model line, we see that both the direction and the amplitude of the variations of the current account ratio are at variance with the model's results.

This simple exercise shows that, while elaborating on this oversimplified RBC open-economy model may yield interesting new results, the analysis presented in this paper is robust enough to the closed-economy hypothesis.

\subsection{Extension: Shocks on $r^{*}$}

We may speculate whether adding an additional source of fluctuations, one more directly linked to the international dimension than TFP, would improve on the results obtained so far. To explore this conjecture, I ran the same simulation as above, but assumed that the world interest rate, $r^{*}$, was subject to an exogenous external shock, $\epsilon_{t}$, such that

$$
r_{t}^{*}=\frac{\gamma}{\beta}-1+\epsilon_{t}
$$

The shock series is obtained as the difference between the "theoretical" $r^{*}$ used in the previous simulation and the ex post real interest rate observed for Belgium in the data. The shock $\epsilon_{t}$ is assumed to be 0 in the steady state.

The results of this exercise improve on the previous results for the behaviour of output and labour input, particularly as concerns the years 1933-34 (see Figures 33, 34 and 35). However, the price of such an improvement is an abnormal volatility of investments and the current account, which are at variance with the data. This casts a shadow over the overall reliability of the results, and leads me to stick to my previous conclusion that, prima facie at least, the closed-economy analysis presented in this paper is relatively robust.

\footnotetext{
${ }^{18}$ The typical model encompasses adjustment costs on capital, which I refrain from including for the sake of comparability with the previous models. Intuitively, the presence of adjustment costs on capital will kill the excess volatility shown by the model at the end of the decade. At the same time, it is likely to worsen the predictive capacity of the model for the initial drop.
} 


\section{Conclusions}

This paper gives partial support to the accepted wisdom among historians, that the Great Depression in Belgium was essentially a monetary phenomenon, due to an external shock and propagated via sticky nominal wages.

Results show that a DSGE model with nominal wage staggering à la Taylor and monetary shocks gives a reliable way of modelling the onset of Great Depression in Belgium. On the other hand, the contribution of TFP shocks appears to be slim, no matter whether cast in a perfect-competition, flexibleprice model or in a sticky-wage environment. Introducing war expectations into the baseline RBC model produces little improvement on the results.

None of the models considered in this paper is able to account for the absence of recovery after the 1935 devaluation. Further research is therefore necessary to achieve a better understanding of the second half of the 1930s in Belgium.

As explained in the text, I used monetary shocks as a shortcut for exchange rates problems. If such a perspective is arguably a good first approximation, a more complete analysis of the Belgian Great Depression should go beyond the shortcut, and face the open-economy issues. Data show that Belgian imports and exports comprised as much as $30 \%$ of income in the interwar period. We know from historians that Belgian industries typically concentrated on the production of highly-standardised semi-manufactured goods for foreign markets (Hogg (1986), Mommen (1994)). Hence, it is safe to say that Belgium showed all the characteristics of the typical small open economy. Moreover, Belgium had an important bilateral relationship with the United Kingdom. These two characteristics make the Belgian case suitable for analysis within two different frameworks in international macroeconomics. One is the small-open-economy version of the standard RBC model. Originally advanced by Mendoza (1991) in a pure RBC perspective, such a framework has recently been enriched by Galì and Monacelli (2005) in a New Keynesian fashion, merging money, nominal frictions and monopolistic competition with the small-open-economy RBC model. In Section 8, I took a first step in this direction, by considering a baseline open-economy version of the standard RBC model. The results were not satisfactory, as no new information on the Belgian Great Depression was gained. This was possibly due to the assumed oversimplified theoretical structure, that excluded monetary phenomena.

Alternatively, we can think of using a two-country framework for modelling Belgium and the United Kingdom in the 1930s. This class of models was pioneered in modern macroeconomics by Backus, Kehoe, and Kydland (1992) within a pure RBC set-up. It was then extended to a New Keynesian framework by Obstfeld and Rogoff (1995), and nowadays many versions 
exist. ${ }^{19}$ Such extensions are left for future research.

\section{References}

Backus, D. K., P. J. Kehoe, and F. E. Kydland (1992): "International Real Business Cycles," Journal of Political Economy, 100, 745-775.

Banque Nationale De Belgique (1943a): Statistiques Economiques Belges, 1919-1928.

(1943b): Statistiques Economiques Belges, 1929-1940.

Baudhuin, F. (1946): Histoire Economique de la Belgique 1914-1939. Etablissements Emile Bruylant, Bruxelles.

(1961): Belgique 1900-1960: Explication Economique de Notre Temps. Editions J. Duculot, Gembloux.

Beaudry, P., And F. Portier (2002): "The French Depression in the 1930s," Review of Economic Dynamics, 5, 73-99.

Bordo, M. D., C. J. Erceg, and C. L. Evans (2000): "Money, Sticky Wages and the Great Depression," American Economic Review, 90, 14471463.

BuYst, E. (1997): "New GNP Estimates for the Belgian Economy during the Interwar Period," Review of Income and Wealth, 43, 357-375.

Cahuc, P., And A. Zylberberg (2004): Labor Economics. MiT Press, Cambridge, USA.

Carlstrom, C. T., and T. S. Fuerst (2001): "Timing and Real Indeterminacy in Monetary Models," Journal of Monetary Economics, 47, $285-298$.

Cassiers, I. (1989a): Croissance, Crise et Régulation en Economie Ouverte: La Belgique entre les Deux Guerres. De Boeck Université, Bruxelles.

_ (1989b): "Hourly Wage Statistics in Belgian Industry, 1919-1939," in The Economic Development of Belgium since 1870, ed. by H. V. der Wee, and J. Blomme, pp. 369-395. Elgar, Cheltenham, 1997.

\footnotetext{
${ }^{19}$ See Lane (2001) for a survey.
} 
(1995): "Managing the Franc in Belgium and France: The Economic Consequences of Exchange-Rate Policies, 1925-1936," in Banking, Currency and Finance in Europe between the Wars, ed. by C. Feinstein. Clarendon Press, Oxford.

Christiano, L., R. Motto, and M. Rostagno (2004): "The Great Depression and the Friedman-Schwartz Hypothesis," Working Paper 10255, National Bureau of Economic Research.

Cole, H. L., and L. E. Ohanian (1999): "The Great Depression in the United States from a Neoclassical Perspective," Federal Reserve of Minneapolis Quarterly Review, 23, 2-24.

(2002): "The Great UK Depression: A Puzzle and a Possible Resolution," Review of Economic Dynamics, 5, 19-44.

(2004): "New Deal Policies and the Persistence of the Great Depression: A General Equilibrium Analysis," Journal of Political Economy, $112,779-816$.

Cole, H. L., L. E. Ohanian, and R. Leung (2005): "Deflation and the International Great Depression: A Productivity Puzzle," Working Paper 11237, National Bureau of Economic Research.

Comin, D., and B. HobiJn (2004): "Cross-Country Technological Adoption: Making the Theories Face the Facts," Journal of Monetary Economics, pp. 39-83.

Correia, I., J. C. Neves, and S. Rebelo (1995): "Business Cycles in a Small Open Economy," European Economic Review, 39, 1089-1113.

De Vroey, M., and L. Pensieroso (2006): "Real Business Cycle Theory and the Great Depression: the Abandonement of the Abstentionist Viewpoint," Contributions to Macroeconomics, 6, issue 1, article 13.

Eichengreen, B. (1992): Golden Fetters: The Gold Standard and the Great Depression, 1919-1939. Oxford University Press, Oxford.

Fisher, J. D. M., And A. Hornstein (2002): "The Role of Real Wages, Productivity, and Fiscal Policy in Germany's Great Depression 1928-37," Review of Economic Dynamics, 5, 100-127.

Galì, J., And T. Monacelli (2005): "Monetary Policy and Echange Rate Volatility in a Small Open Economy," Review of Economic Studies, 72, 707-734. 
Goossens, M. (1988): "The Belgian Labour Market during the Interwar Period," in The Economic Development of Belgium since 1870, ed. by H. V. der Wee, and J. Blomme, pp. 417-429. Elgar, Cheltenham, 1997.

Goossens, M., S. Peeters, and G. Pepermans (1988): "Interwar Unemployment in Belgium," in Interwar Unemployment in International Perspective, ed. by B. Eichengreen, and T. J. Hatton, pp. 289-324.

HogG, R. L. (1986): Structural Rigidities and Policy Inertia in Inter-War Belgium. Royal Academy of Belgium, Bruxelles.

Kehoe, T. J., and E. C. Prescott (2002): "Great Depressions of the 20th Century," Review of Economic Dynamics, 5, 1-18.

Kim, S. H., And M. A. Kose (2003): "Dynamics of Open-Economy Business-Cycle Models: Role of the Discount Factor," Macroeconomic Dynamics, 7, 263-290.

Lane, P. R. (2001): "The New Open Macroeconomics: A Survey," Journal of International Economics, 54, 235-266.

Maddison, A. (1995): L'Economie Mondiale 1820-1992: Analyse et Statistiques. OECD, Paris.

MendozA, E. G. (1991): "Real Business Cycles in a Small Open Economy," American Economic Review, 81, 797-818.

Merz, M. (1995): "Search in the Labor Market and the Real Business Cycle," Journal of Monetary Economics, 36, 269-300.

Ministere des Affaire Economiques (1943): Démographie de la Belgique. Bruxelles.

Mommen, A. (1994): The Belgian Economy in the Twentieth Century. Routledge, London.

Obstfeld, M., and K. Rogoff (1995): "Exchange Rate Dynamics Redux," Journal of Political Economy, 103, 624-660.

(1996): Foundations of International Macroeconomics. MIT Press, Cambridge, USA.

Pensieroso, L. (2007): "Real Business Cycle Models of the Great Depression: A Critical Survey," Journal of Economic Surveys, 21, 110-142. 
Perri, F., And V. QuAdrini (2002): "The Great Depression in Italy: Trade Restrictions and Real Wage Rigidities," Review of Economic Dynamics, 5, 128-151.

Prescott, E. C. (1999): "Some Observations on the Great Depression," Federal Reserve Bank of Minneapolis Quarterly Review, 23, 25-31.

Schmitt-Grohé, S., And M. Uribe (2003): "Closing Small Open Economy Models," Journal of International Economics, 61, 163-185.

TAYlor, J. B. (1980): "Aggregate Dynamics and Staggered Contracts," Journal of Political Economy, 88, 1-23.

van Meerten, M. (2003): Capital Formation in Belgium, 1900-1995. Leuven University Press, Leuven.

Vanthemsche, G. (1987): "The Economic Action of the Belgian State during the Crisis of the 1930s," in The Economic Development of Belgium since 1870, ed. by H. V. der Wee, and J. Blomme, pp. 337-356. Elgar, Cheltenham, 1997.

Walsh, C. E. (2003): Monetary Theory and Policy. MIT Press, Cambridge, USA.

Weder, M. (2006): "The Role of Preference Shocks and Capital Utilization in the Great Depression," International Economic Review, 47, 1247-1268.

\section{Appendix: Data}

\section{Real Interest Rate}

Nominal interest rates are monthly nominal returns on Belgian irredeemable bonds, expressed on a yearly basis $\left(i_{y}\right)$. Real interest rates are computed in the following way. Using the monthly retail price index, a monthly rate of inflation is computed. Then, a monthly-based interest rate $i_{m}$ is calculated according to the simple no-arbitrage rule

$$
\left(1+i_{y}\right)=\left(1+i_{m}\right)^{12} \text {. }
$$

Next, I worked out a series for the monthly-based real interest rate $\left(r_{m}\right)$, assuming a static version of the Fisher equation,

$$
i_{t}=r_{t}+E_{t-1} \pi_{t}
$$


with $E_{t-1} \pi_{t}=\pi_{t}$. Finally, I used Equation 22 to obtain a yearly-based monthly series for the real interest rate $\left(r_{y}\right)$.

The series so obtained covers the period 1920:1-1940:2. It shows high volatility, and seasonal components. In order to smooth the series and get rid of seasonality, I computed a new series $\tilde{r}_{y}$ as a 12-periods moving average of $r_{y}$. The new series covers the 1921:1-1940:2 subperiod, and is the one graphed in Figure 4.

\section{Unemployment Rate}

Monthly unemployment rates are computed in the following way. Using data from the Banque Nationale de Belgique on monthly total working days lost per 1000 insured and per week, I divided each number by 10, to give the monthly working days lost because of unemployment per 100 insured and per week. To get a percentage referring to individuals rather than weeks, I divided the result by 6 , the number of working days in a week. This gives a rough measure of unemployment for several reasons. First, according to the Banque Nationale de Belgique, on December 31st, 1930, the total number of employed was 1,850,272, whereas that of insured workers was just 695,045 . Second, my procedure measures unemployment implicitly as if all the unemployed were without work for the whole month long, which was, of course, not always the case.

\section{Money}

Hogg (1986) provides series on the monetary base, money multiplier and the aggregate M1. While the series for the monetary base is complete, those for the money multiplier and the aggregate M1 lack the 1934 value. I have reconstructed this value as follows. I took the 1934 money multiplier to be the average of the 1933 and the 1935 values. Then I multiplied this multiplier by the 1934 monetary base, to get the 1934 value for M1.

\section{Labour}

I do not have a complete series of labour and employment data for the interwar years. Maddison (1995) reports data on total employment, labour force, annual hours worked per worker, and total hours worked for the years 1913, 1929, 1938, 1950, 1960, 1973, 1987. Unemployment rates from 1921 to 1938 and from 1950 to 1989 are also reported. I used these data to build an artificial series of total employment in the following way. Taking the two values 
of the labour force in 1913 and 1929, I computed a constant compounded rate of growth of the labour force $g_{(13,29)}^{l f}$ using the formula

$$
(1+g)=\sqrt[n]{\frac{x_{n}}{x_{0}}}
$$

I repeated this exercise for each subsequent two values, so as to obtain $g_{(29,38)}^{l f}$, $g_{(50,60)}^{l f}, g_{(60,73)}^{l f}$, and $g_{(73,87)}^{l f}$. Then, I assumed that the labour force $l f$ evolved at a constant pace in each subperiod. Thus, for instance, the labour force in 1914 will be

$$
l f_{14}=l f_{13}\left(1+g_{(13,29)}^{l f}\right) .
$$

This artificial series of the labour force is then used to obtain a total employment series $(L)$, the variable we are interested in, by using the unemployment rate $(u)$. This is done using this standard formula

$$
L=(1-u) l f,
$$

which uses the fact that the employment and unemployment rates are defined as the ratios of the number of employed and unemployed, respectively, over the labour force, and are therefore complements to 1 .

As is clear from this account, the information about the numbers of employed is basically driven by the unemployment rate.

In order to have an idea of the bias introduced by this procedure, I compared the artificial series with the data provided by the Belgian Planning Bureau for the period 1953-1988. ${ }^{20}$ Results showed similar behaviour for the two series. The artificial series tends to fit the actual one in the mid1960s and in the late 1980s, and to underestimate total employment in the remaining years.

After this robustness check, I rerun the computations, substituting the unemployment rate taken from Goossens, Peeters, and Pepermans (1988), for that used by Maddison. This was done because Maddison's numbers seem to underestimate the unemployment rate. Figure 36 compares the data from different sources. The underestimation appears especially evident during the 1930s.

To get hours worked, I took the employment series, multiplied it first by 48, (the maximum legal working hours per week), and then by 50, (the numbers of per year working weeks in 1929, according to Maddison (1995)).

As for the population of working age, the available data only cover the years 1920, 1930, 1935, 1939. I interpolated such data to obtain a series $(N)$.

\footnotetext{
${ }^{20}$ I thank David de la Croix for providing these data.
} 


\section{Capital}

To the best of my knowledge there exists no complete capital series for the Belgian economy in the interwar period. This means that I had to rely on an estimation. The standard procedure is to estimate capital by using the perpetual-inventory method, that is the relation

$$
K_{t+1}=(1-\delta) K_{t}+I_{t}
$$

A problem with this method is how to obtain a reliable estimate of the initial value $K_{0}$. My choice was to deduce $K_{0}$ from neoclassical growth theory. From the law of motion of capital, we know that

$$
(1+n) K_{t+1}=(1-\delta) K_{t}+I_{t}
$$

where $n$ stands for the growth rate of population, which we assume to be constant in the long run. Calling $g$ the constant growth rate of capital, and solving Equation 28 for $K_{t}$ we get

$$
K_{t}=\frac{I_{t}}{n+g+\delta}
$$

Given that neoclassical theory tells us that, along the balanced growth path, the growth rate of capital is the same as the growth rate of output, I assumed $g$ to be the constant growth rate of output estimated in Section 4.1. Then I took data on investments from van Meerten (2003), which has a long (1900-1960) series expressed in 1936-38 Belgian francs, (which is therefore comparable with the other data used in this study). I assumed $\delta=0.1$ and then applied Equation 29 to get an estimate of capital in 1900. In doing that, I implicitly assumed that the economy was in a steady state in 1900 . From this initial value, I computed a capital series by means of Equation 27.

To take into account the effect of the First World War, I adopted the following procedure. According to Encyclopedia Britannica, Belgium lost between 16 and $20 \%$ of its wealth during the war. I took this to mean that the capital stock in 1919 was 20\% less than it would have there been had been no war. Then I solved the following equation for $\delta$ :

$K_{19}=K_{13}(1-\delta)^{6}+I_{13}(1-\delta)^{5}+I_{14}(1-\delta)^{4}+I_{15}(1-\delta)^{3}+I_{16}(1-\delta)^{2}+I_{17}(1-\delta)+I_{18}$.

In this way I considered physical destruction brought about by the war as an exogenous increase in the constant depreciation rate of capital. Figure 37 shows this estimation and the significance of the correction. 


\section{Figures}

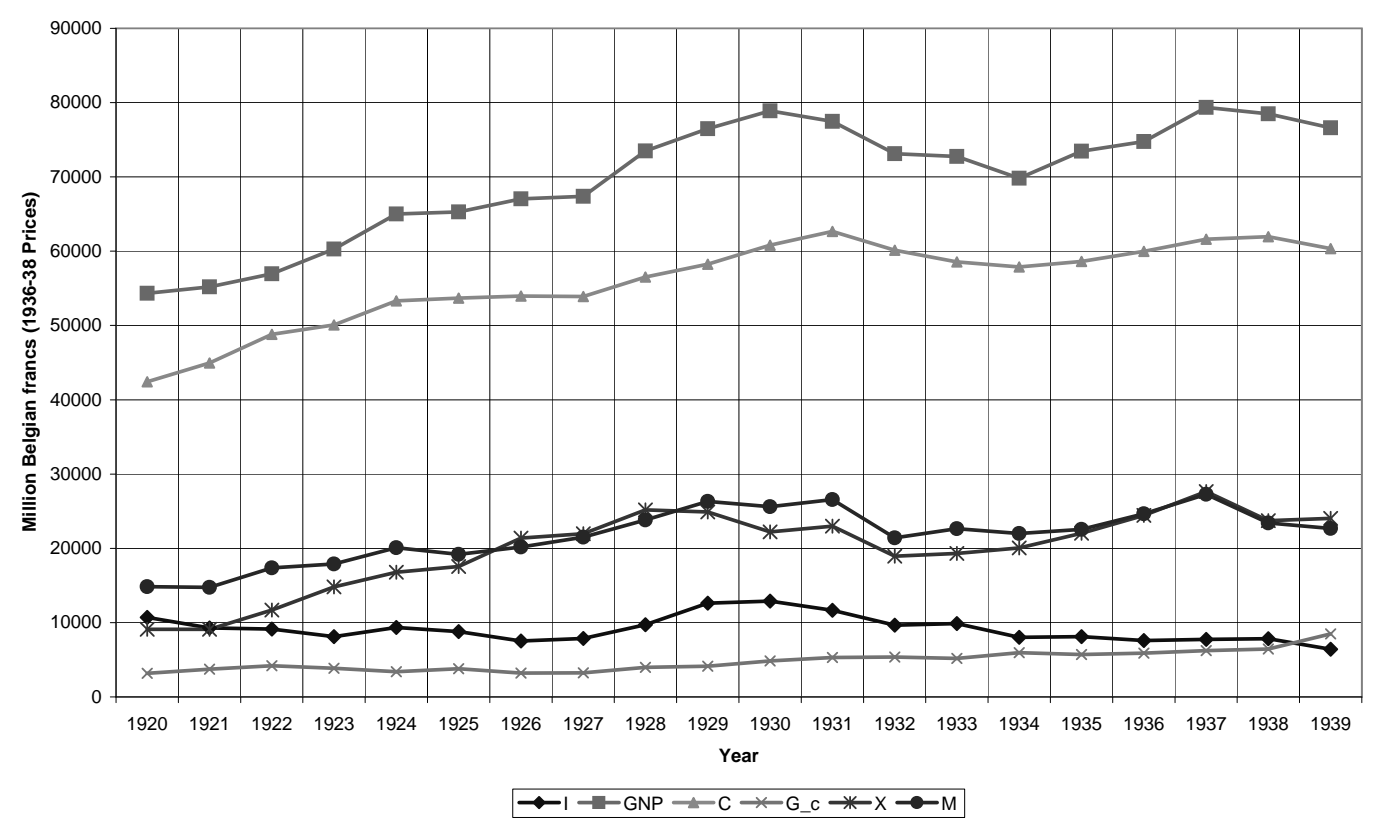

Figure 1: Output and expenditure. Source: Buyst (1997) 


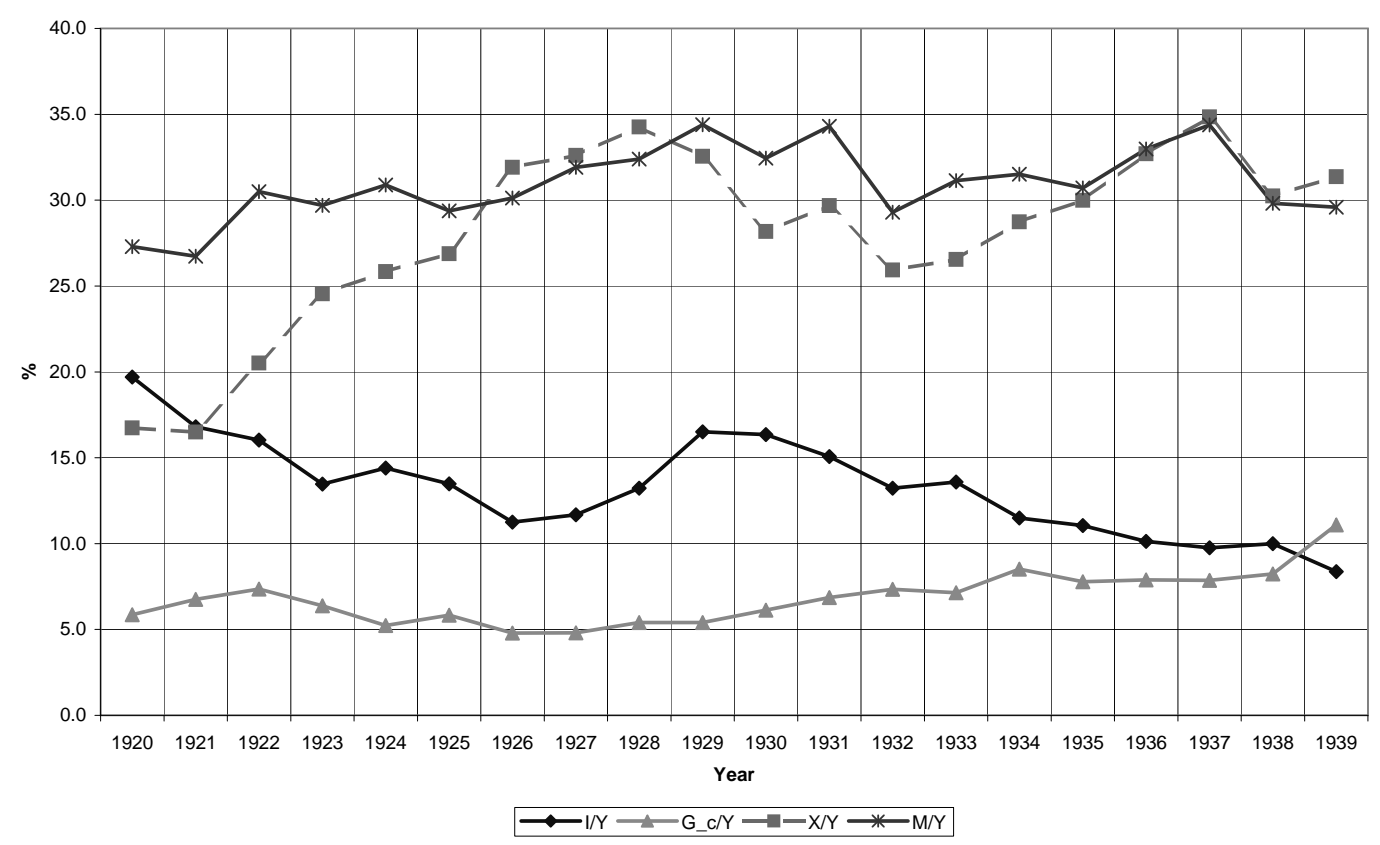

Figure 2: Expenditure as a percentage of output. Source: Buyst (1997)

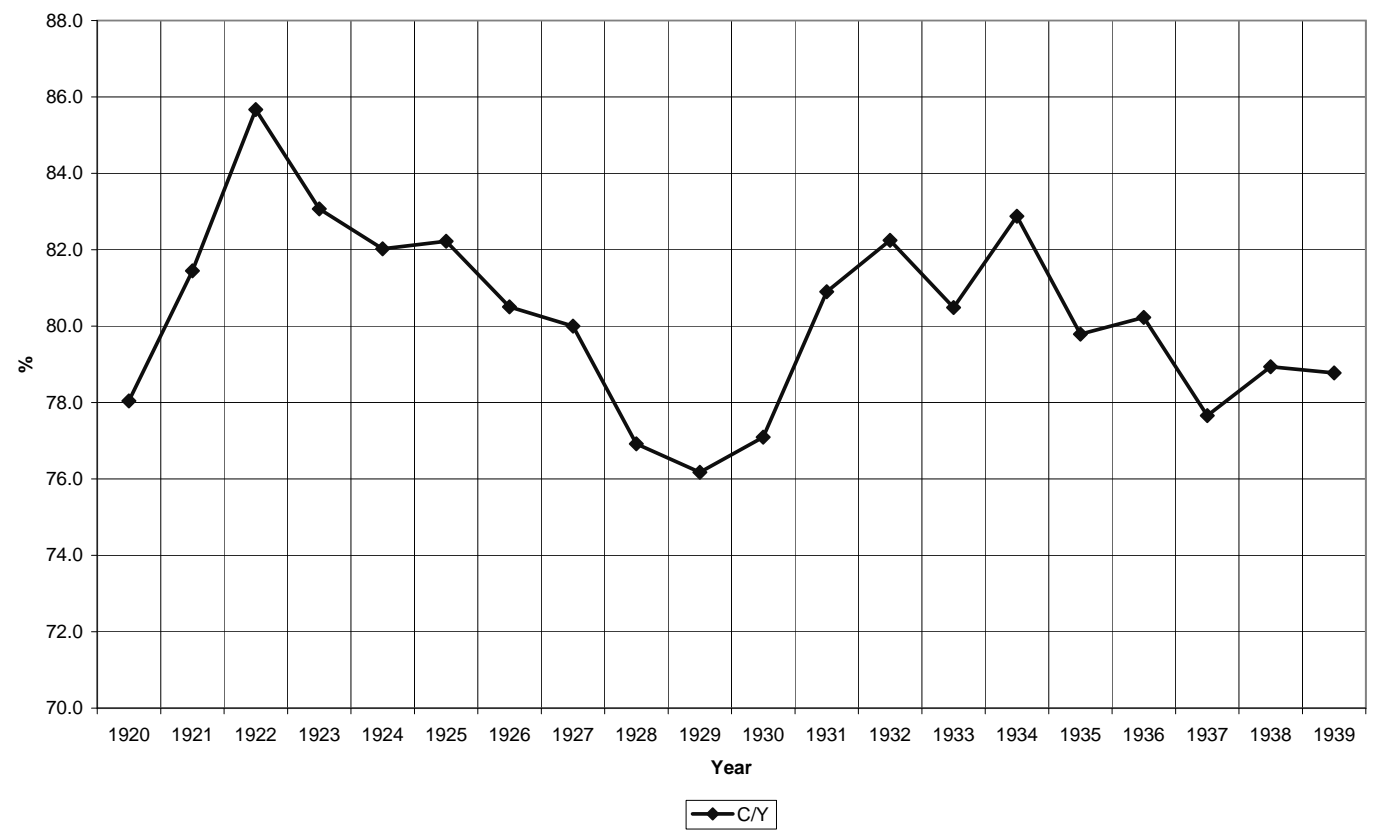

Figure 3: Consumption as a percentage of output. Source: Buyst (1997) 


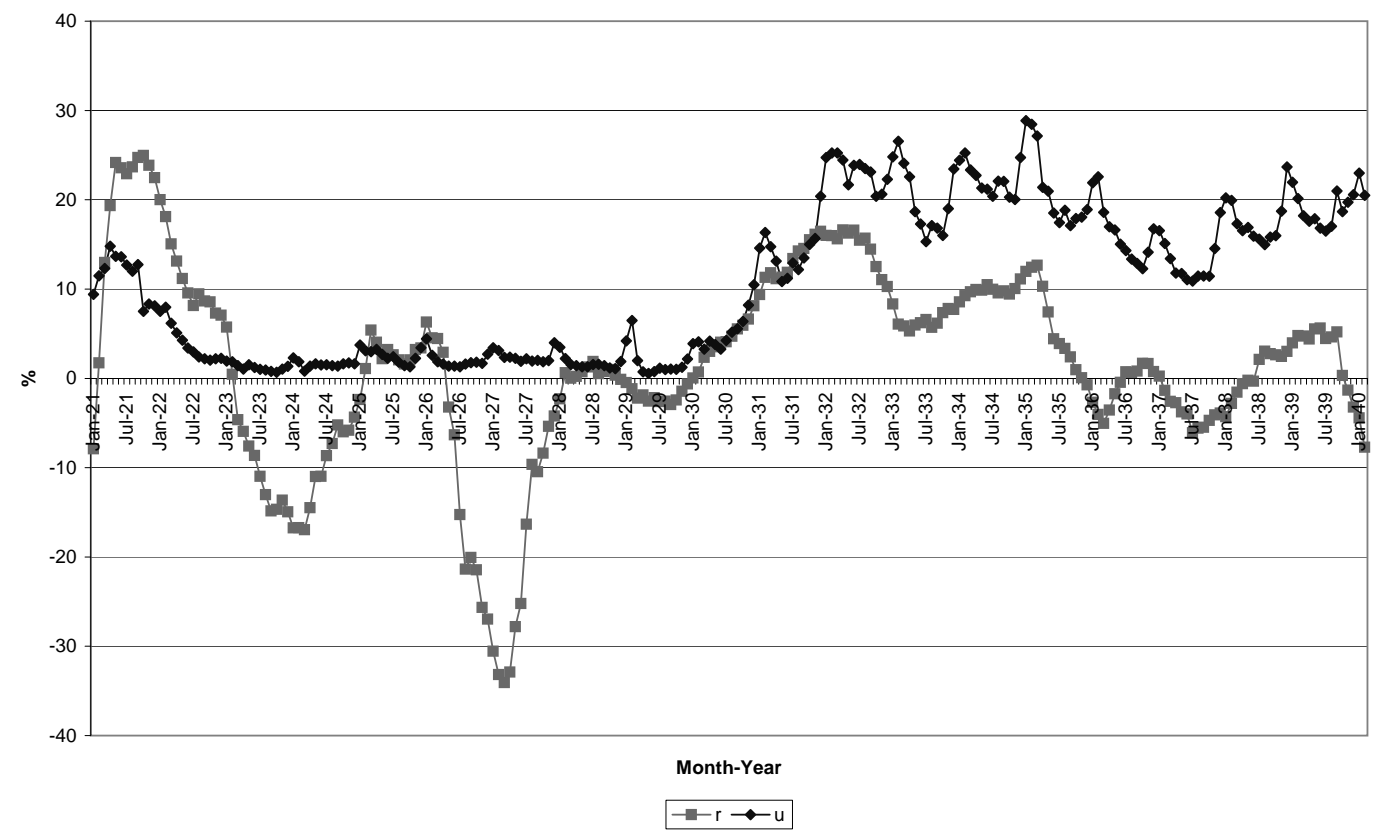

Figure 4: Real interest rate and unemployment rate. Source: My elaboration on Banque Nationale de Belgique (1943a) and Banque Nationale de Belgique (1943b)

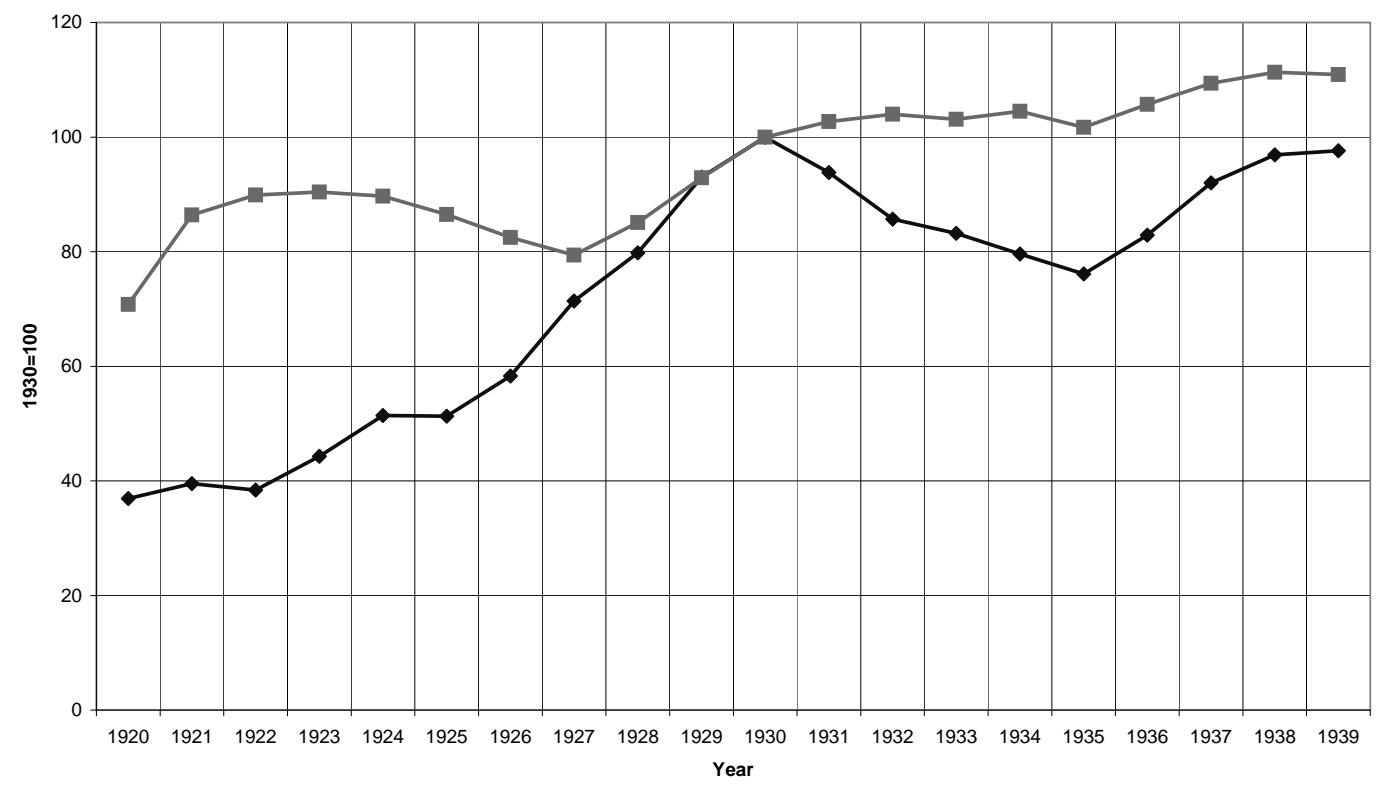

$\rightarrow-$ Nominal Hourly Wages $\rightarrow-$ Real Hourly Wages

Figure 5: Nominal and real wages. Source: Goossens, Peeters, and Pepermans (1988) 


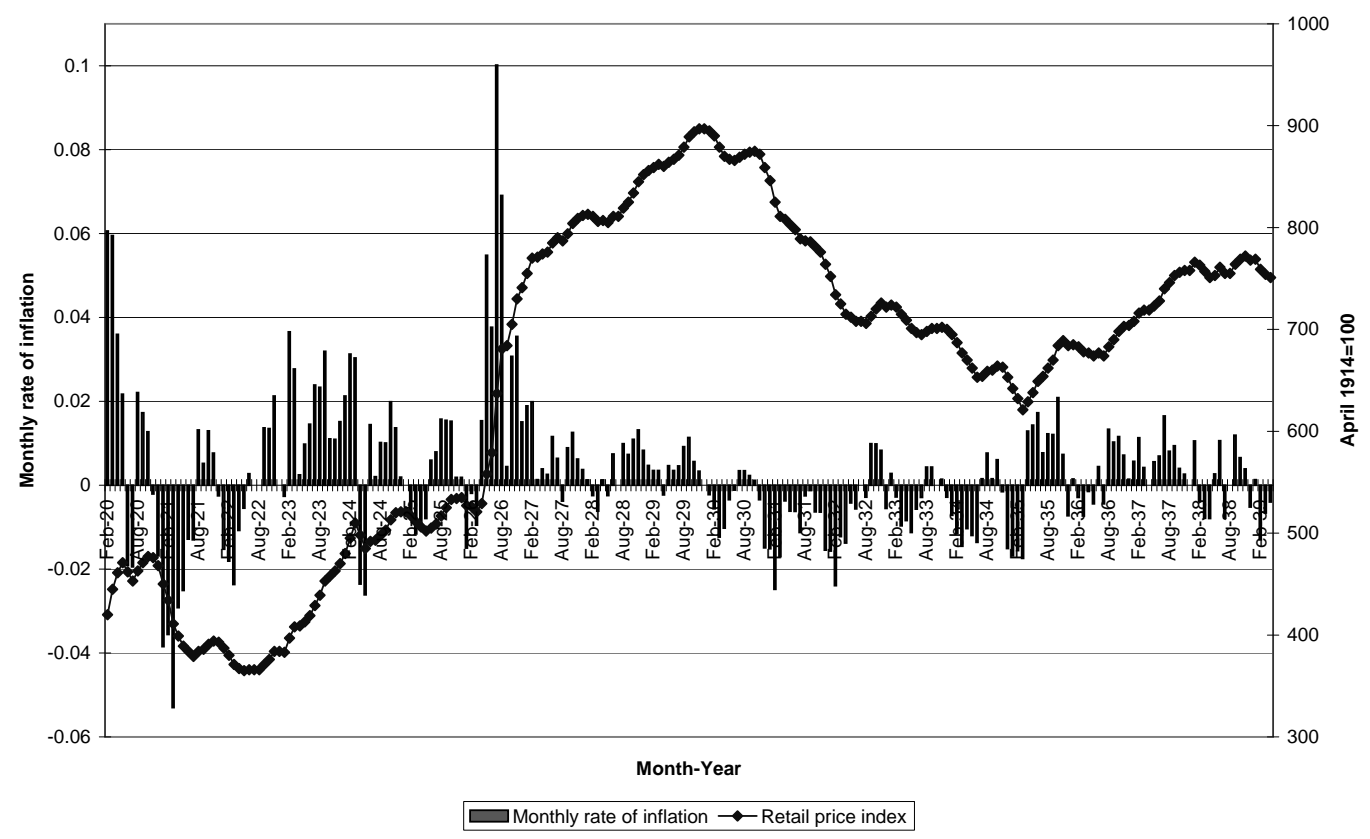

Figure 6: Monthly retail price index and inflation. Source: Banque Nationale de Belgique (1943a) and Banque Nationale de Belgique (1943b)

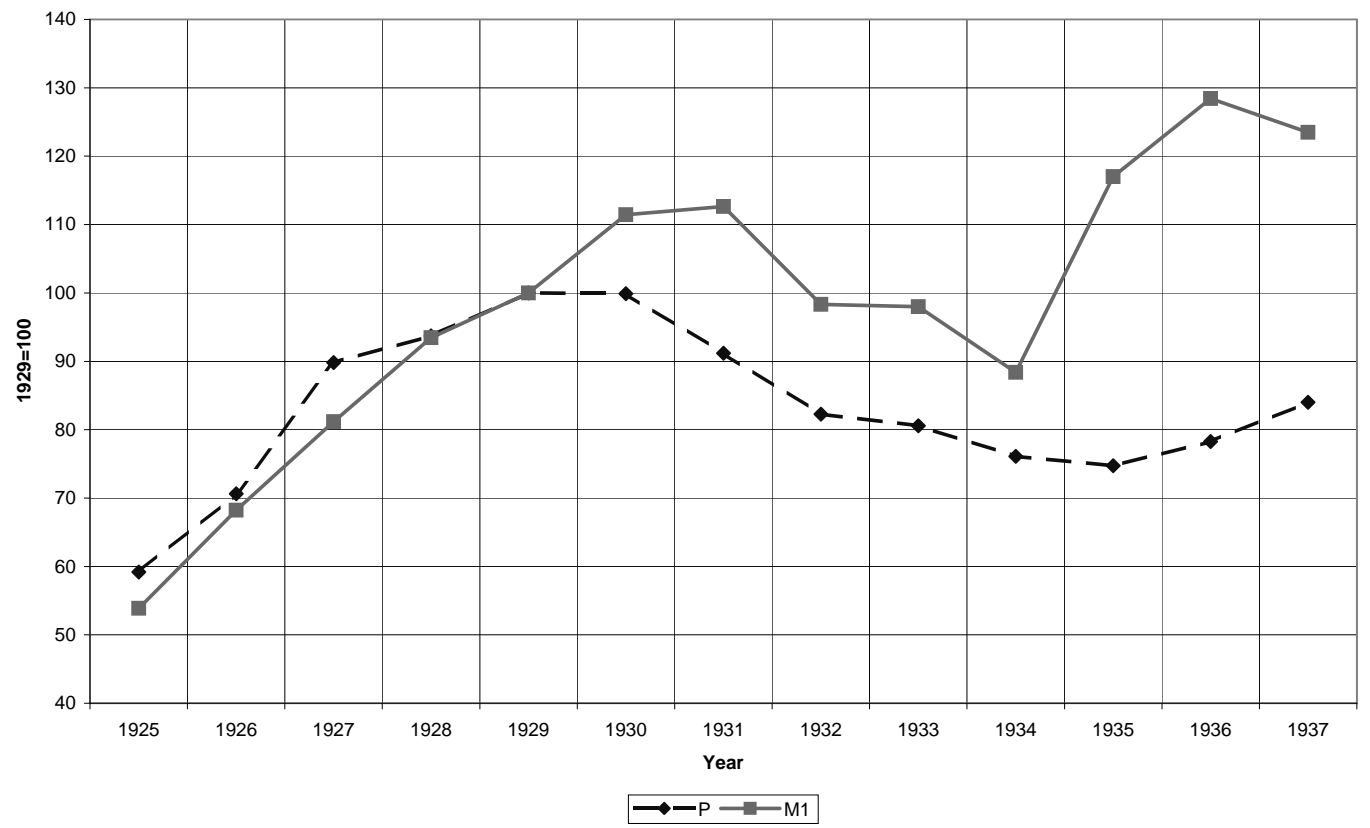

Figure 7: Nominal money supply and retail price index . Sources: Banque Nationale de Belgique (1943a), Banque Nationale de Belgique (1943b) and Hogg (1986) 


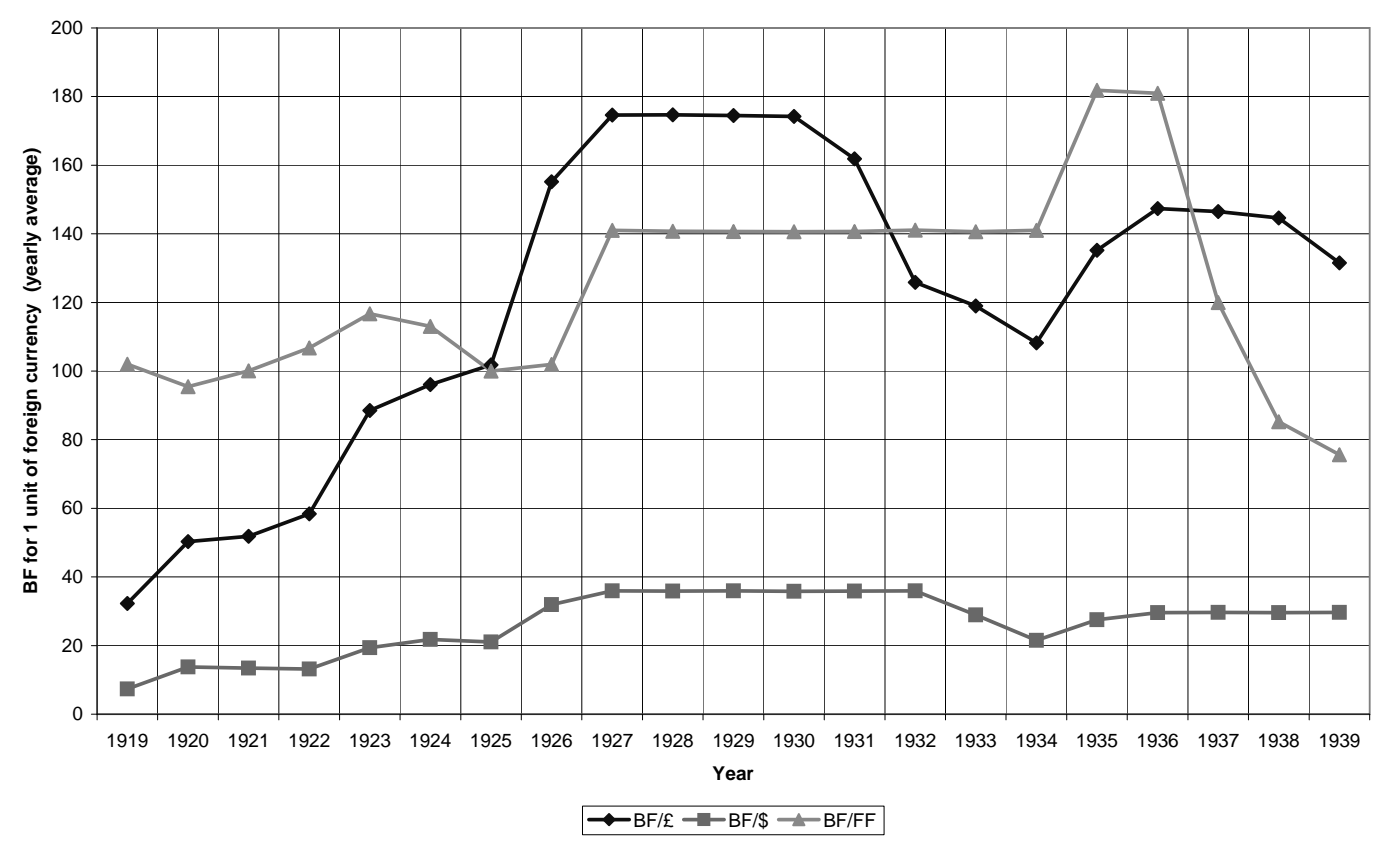

Figure 8: Selected exchange rates, 1919-1939. Source: Baudhuin (1946)

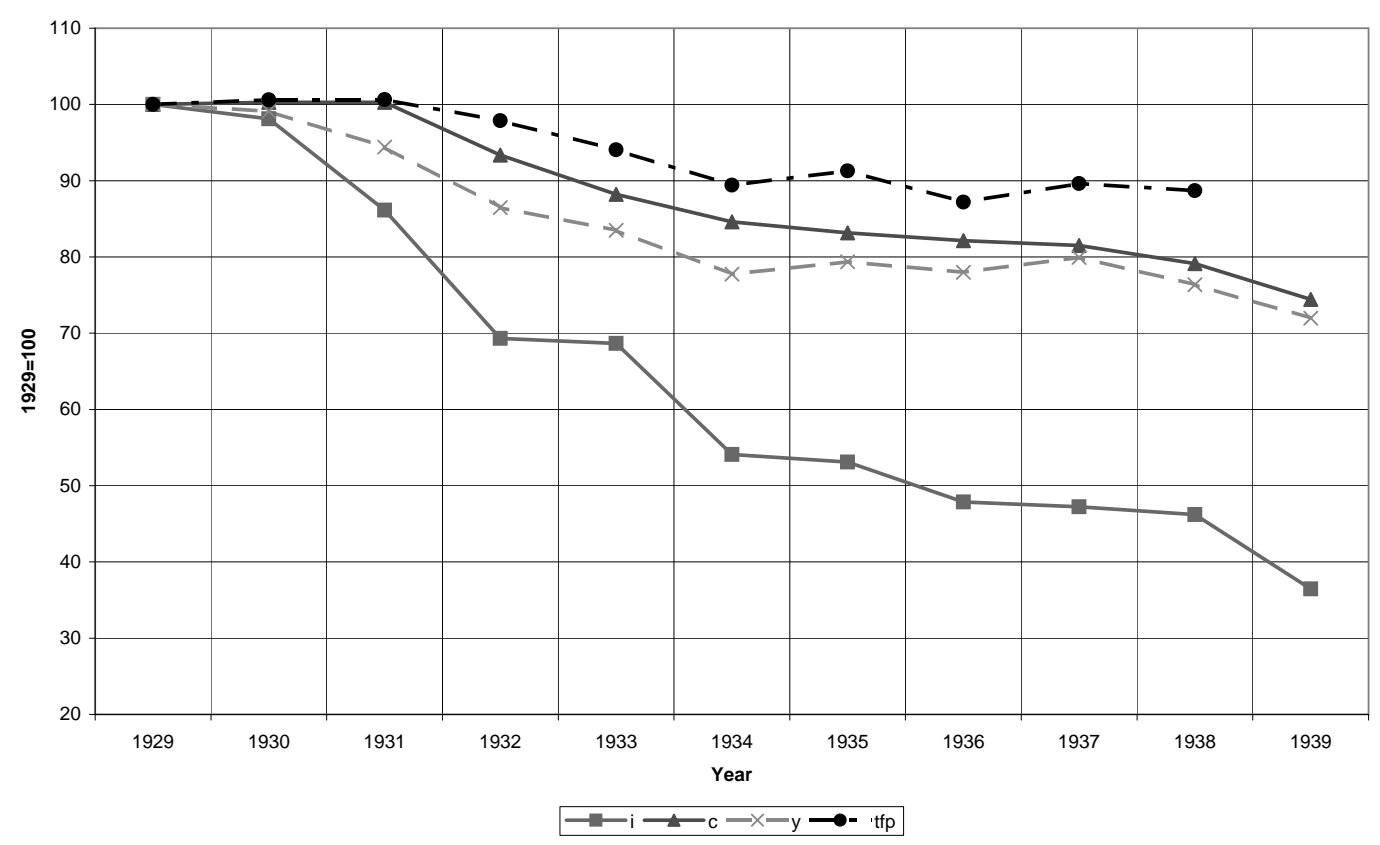

Figure 9: Detrended per capita data. Source: my elaboration on Buyst (1997) 


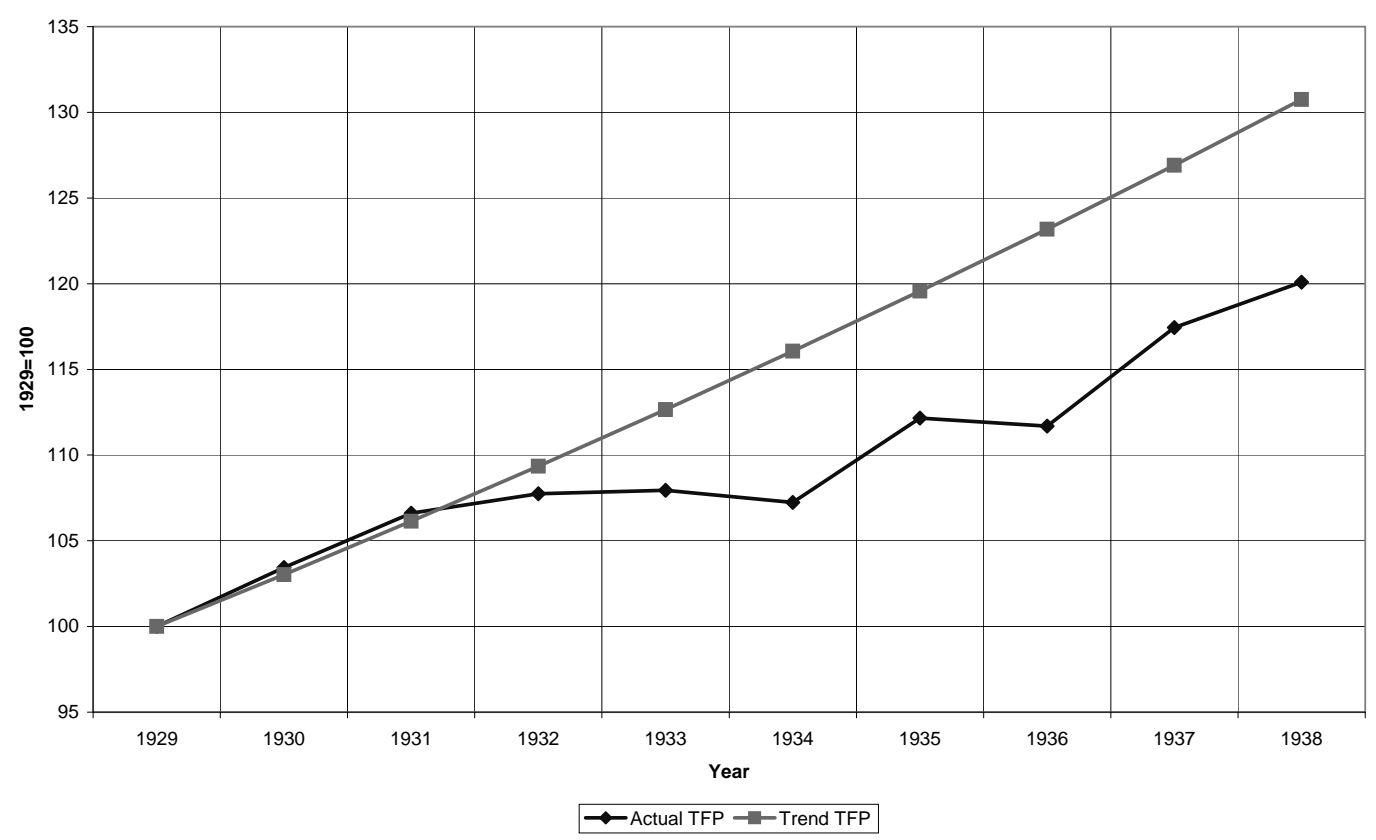

Figure 10: TFP: deterministic trend versus actual values. Source: My elaboration on Buyst (1997) 
Detrended Y
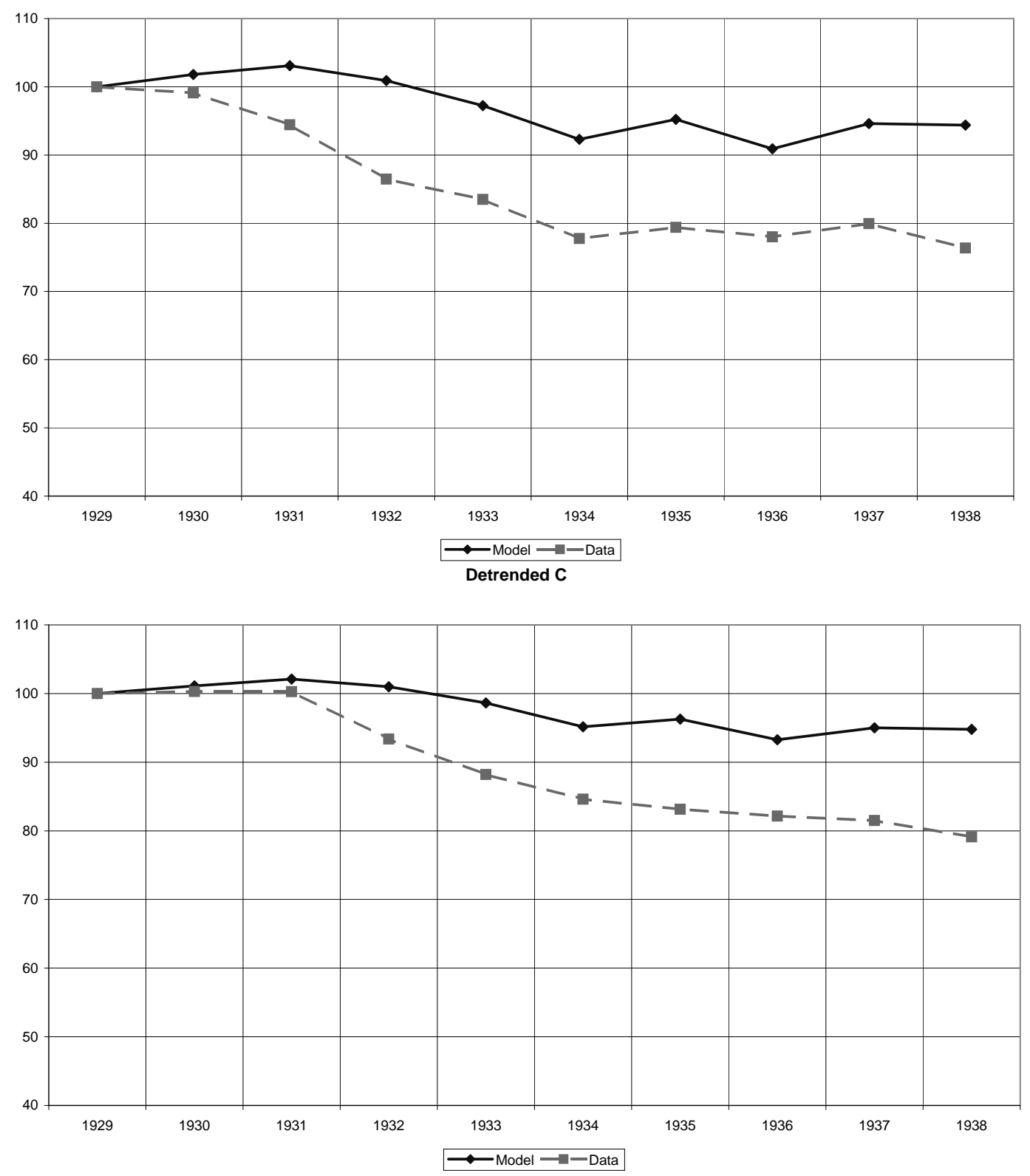

Figure 11: Simulation: RBC model versus actual economy 
Detrended I
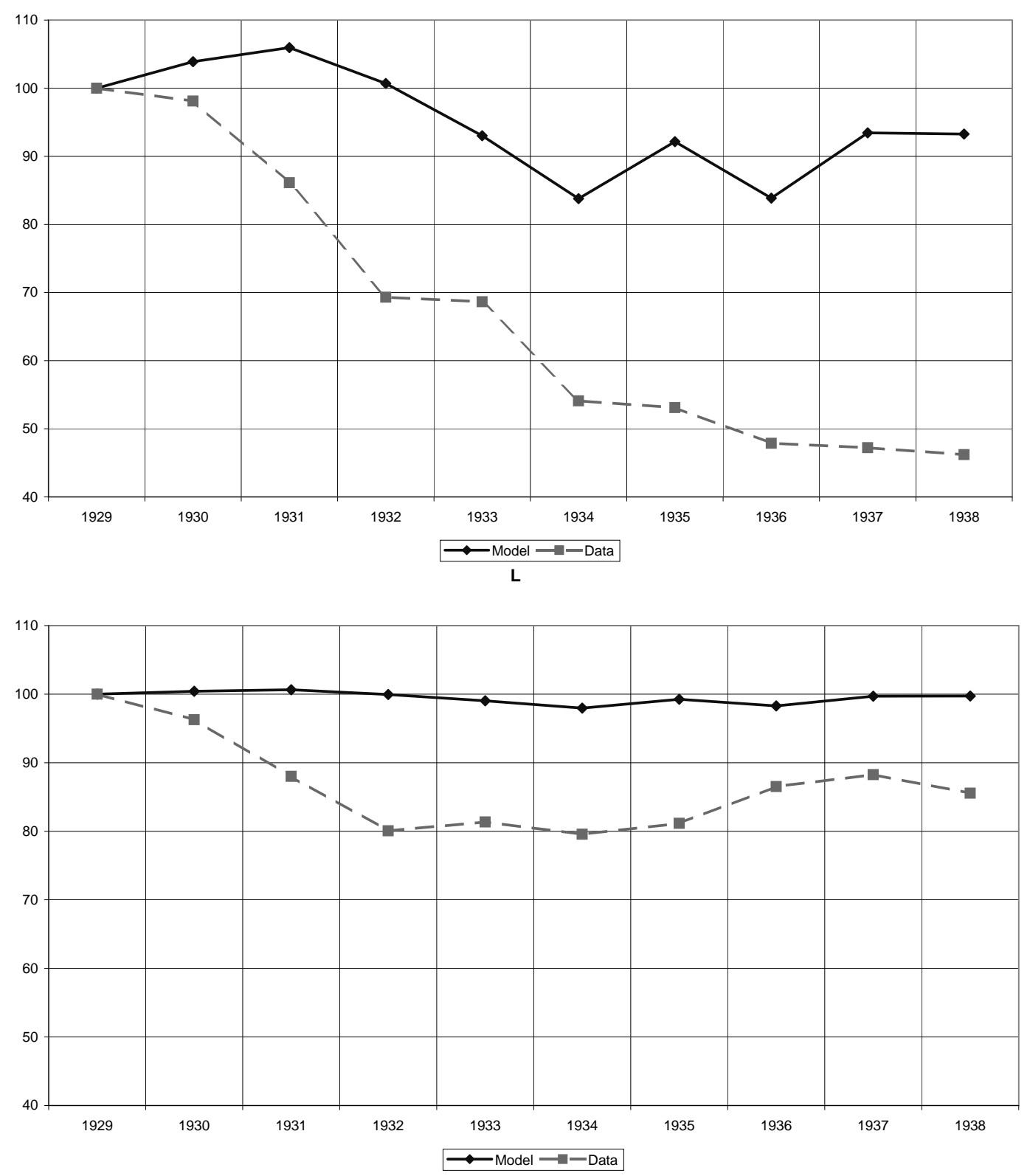

Figure 12: Simulation: RBC model versus actual economy 
Detrended Y
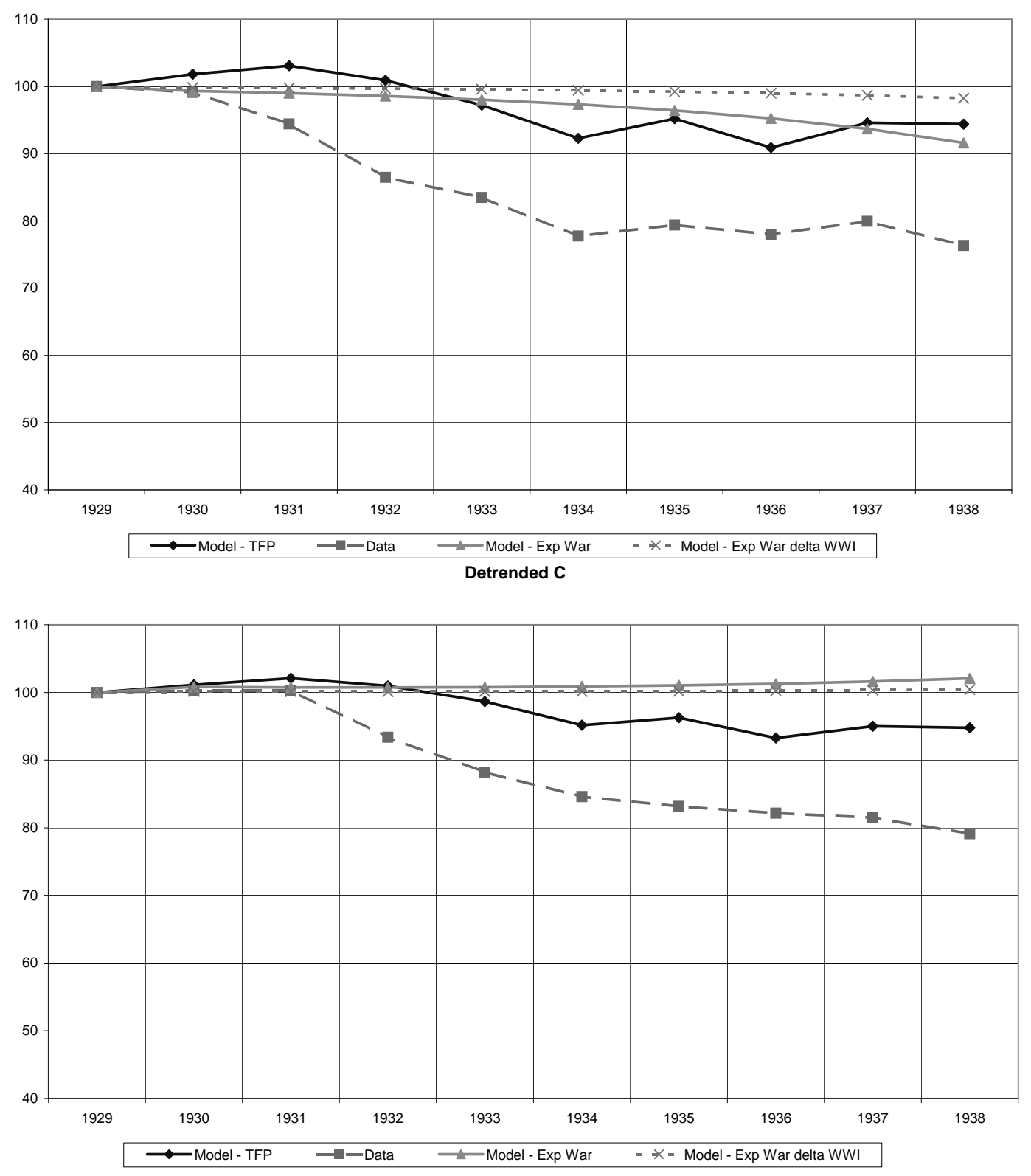

Figure 13: Simulation: RBC model with unexpected TFP shocks, actual economy and RBC model with war anticipation 
Detrended I
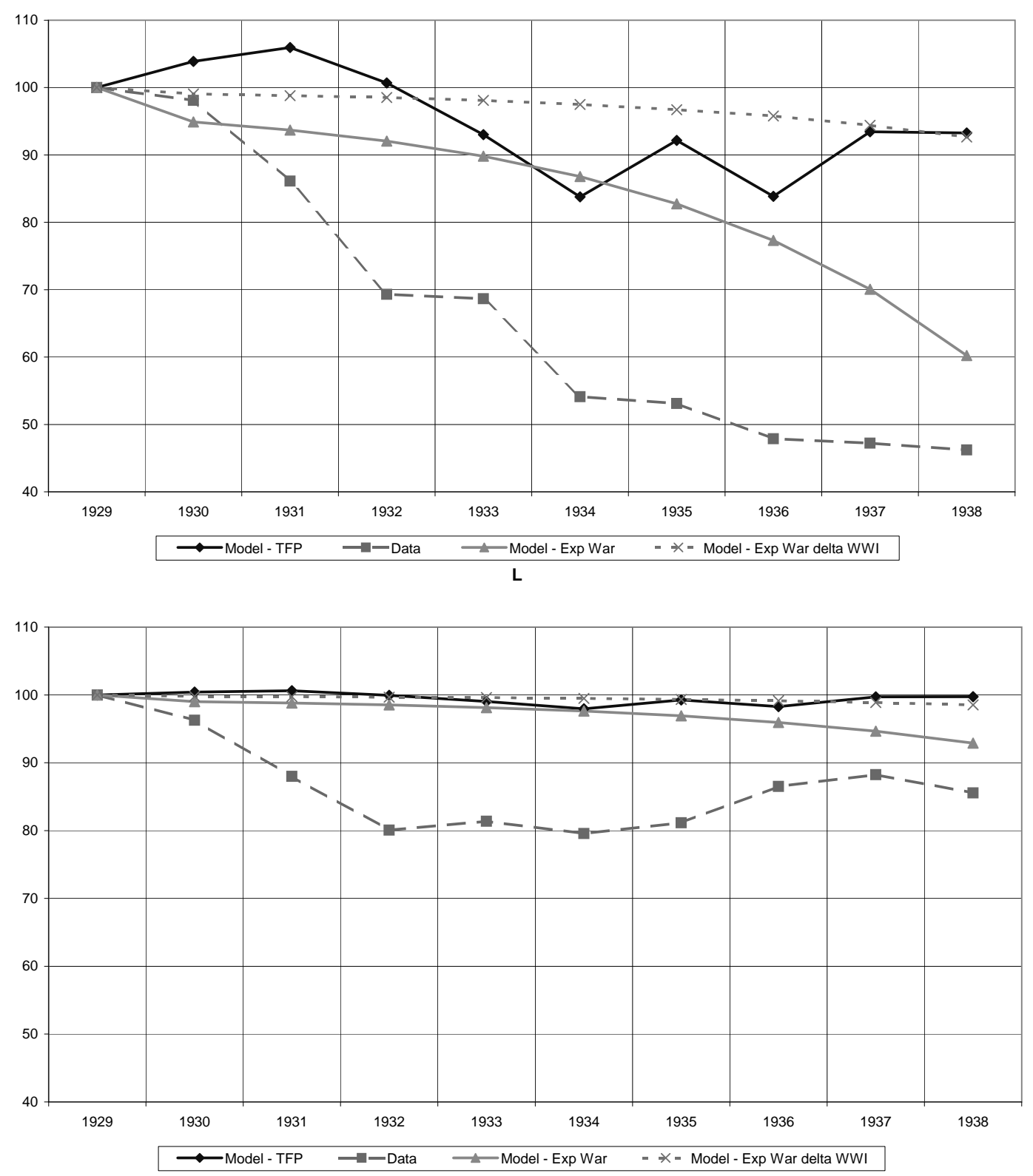

Figure 14: Simulation: RBC model with unexpected TFP shocks, actual economy and RBC model with war anticipation 


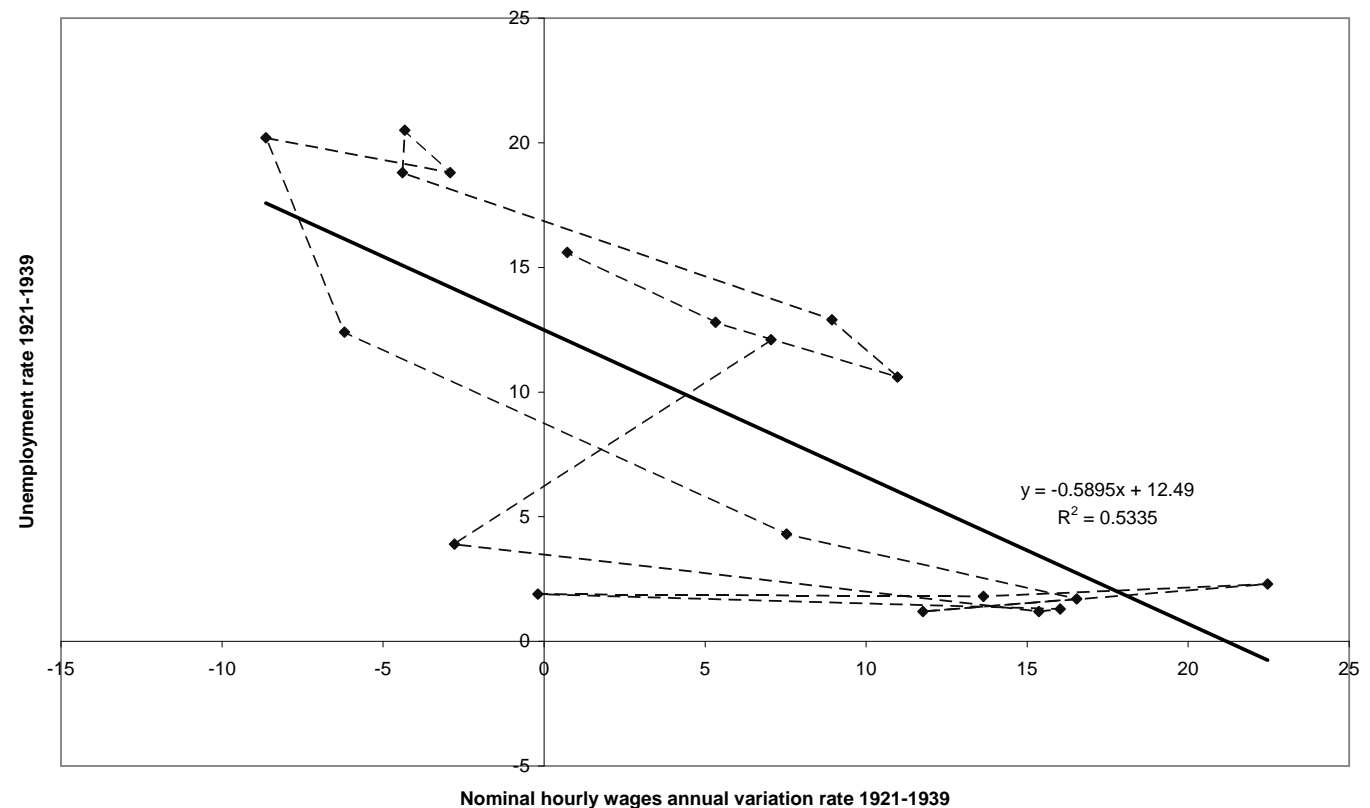

Figure 15: Phillips curve, Belgium 1921-1939. Source: Goossens, Peeters, and Pepermans (1988)

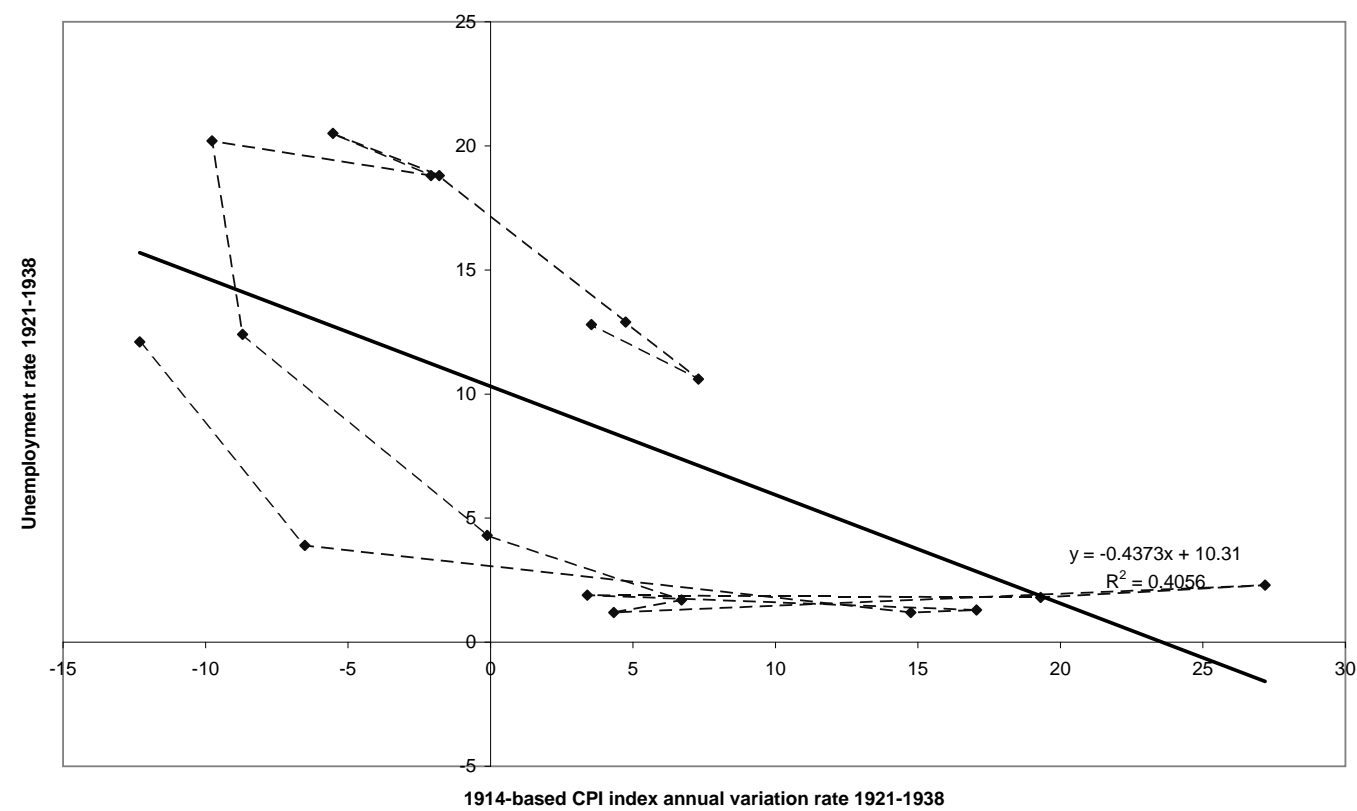

Figure 16: Inflation-unemployment trade-off, Belgium 1921-1938. Sources: Banque Nationale de Belgique (1943a), Banque Nationale de Belgique (1943b) and Goossens, Peeters, and Pepermans (1988) 


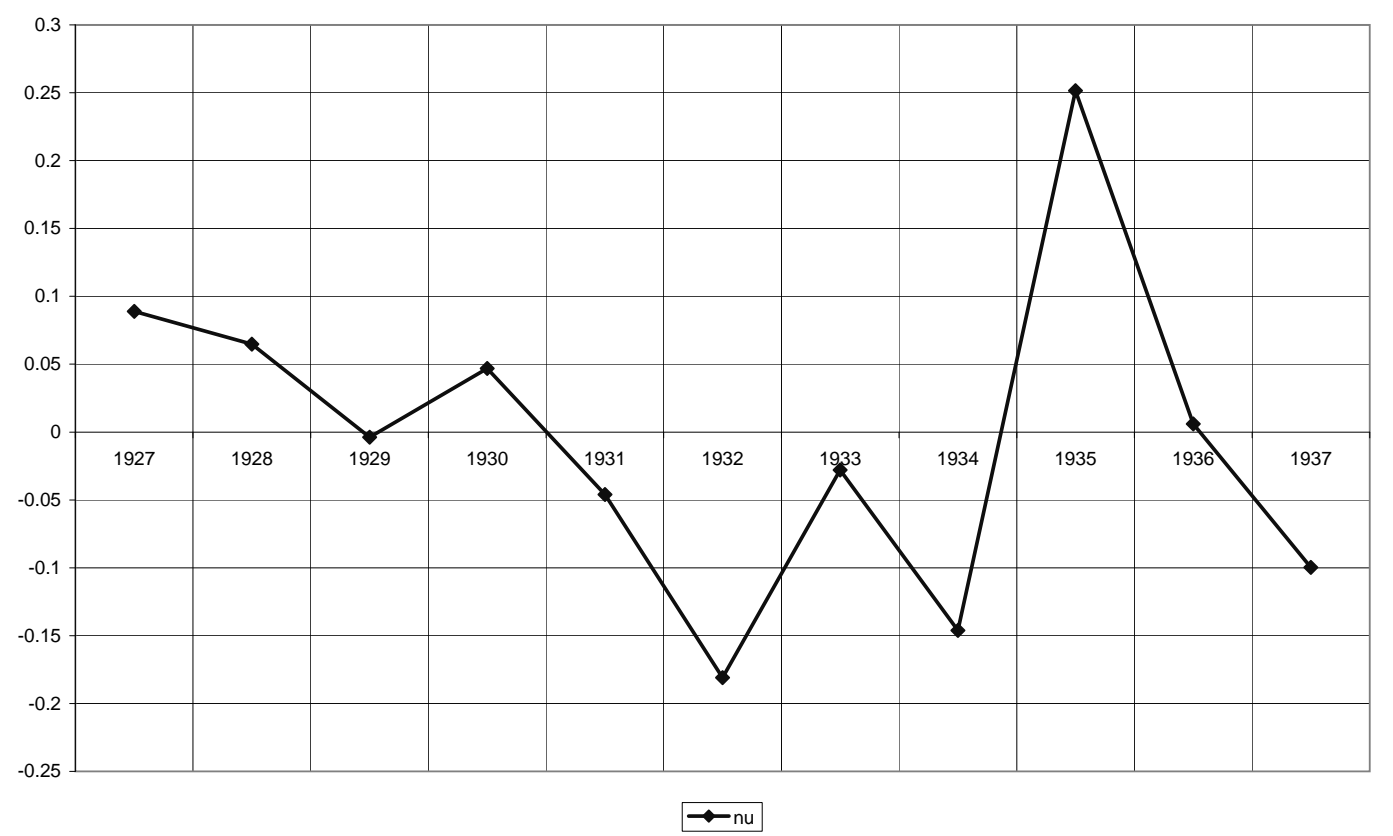

Figure 17: Estimated monetary shock $\nu_{t}$

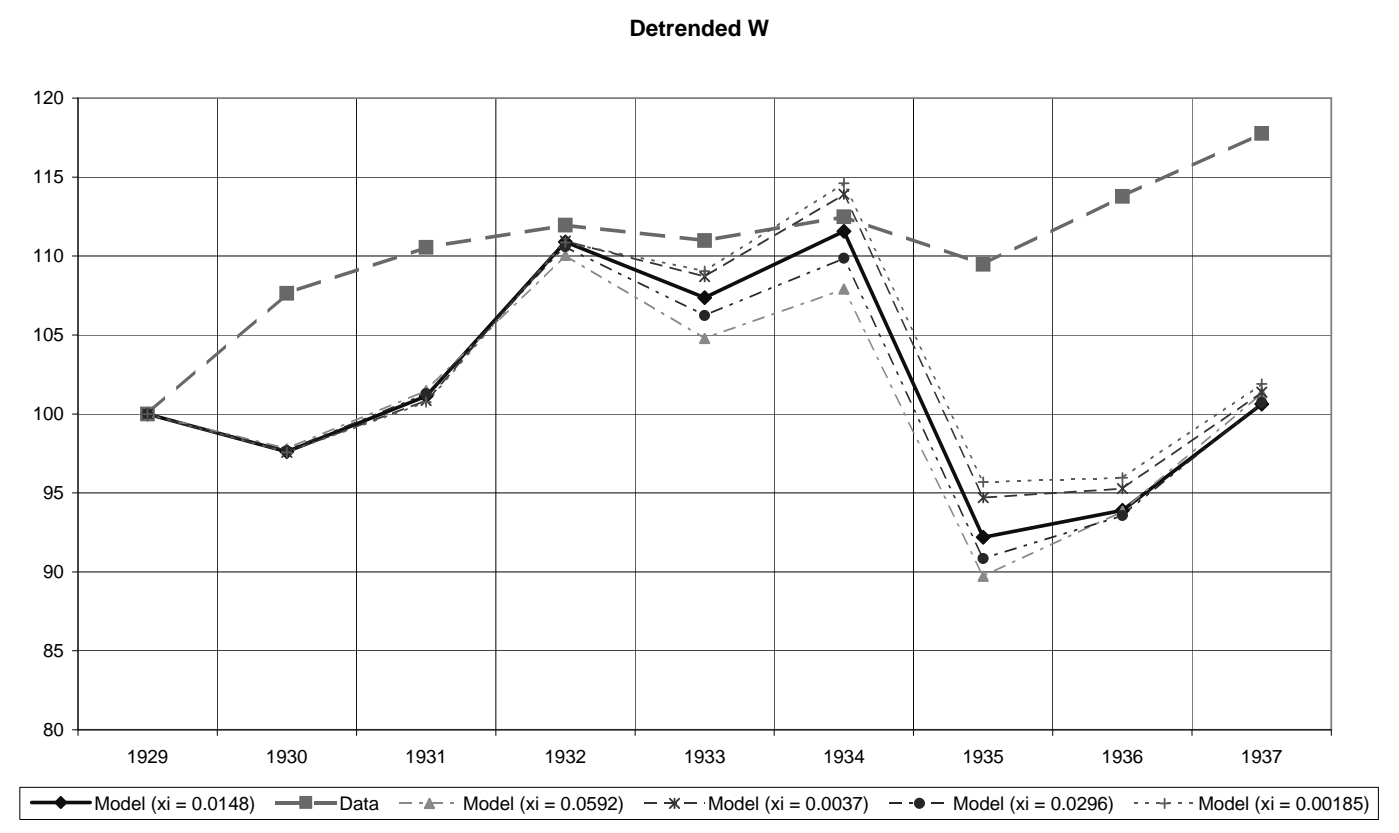

Figure 18: Sensitivity analysis for calibrating $\xi$ : model wages versus actual series. 
Detrended $Y$
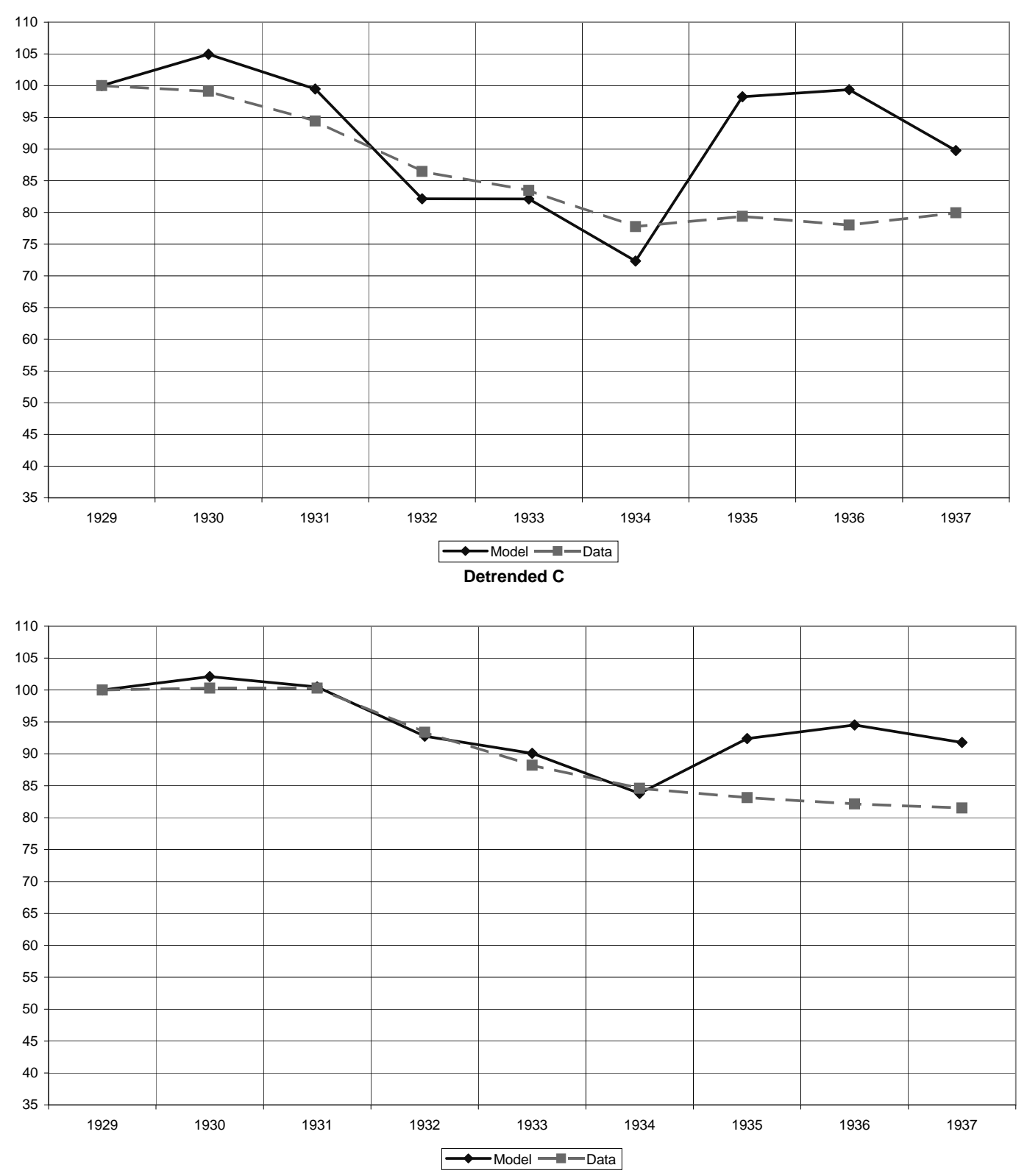

Figure 19: Simulation: model with sticky wages and monetary shocks versus actual data 
Detrended I
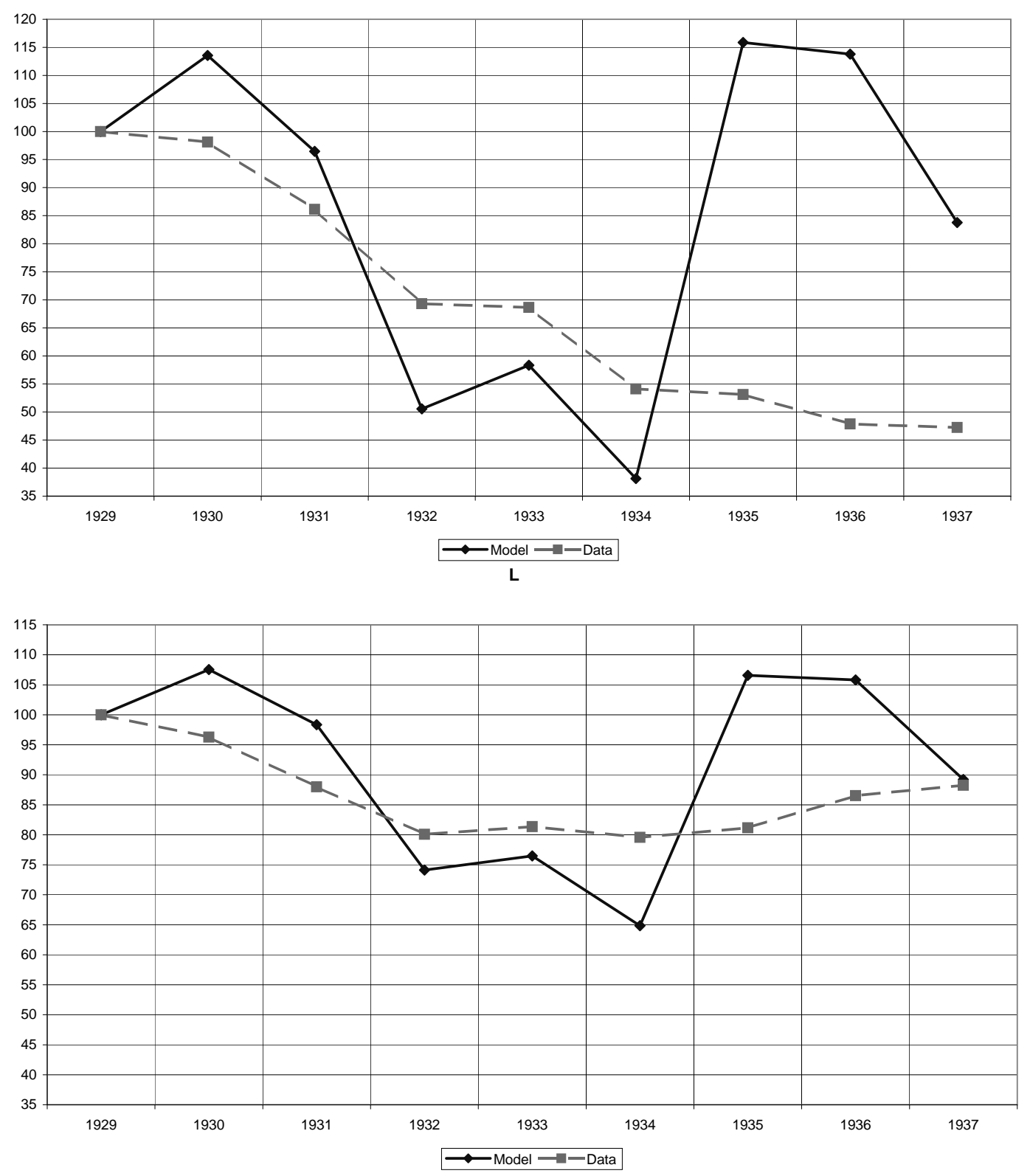

Figure 20: Simulation: model with sticky wages and monetary shocks versus actual data 
Detrended M/P
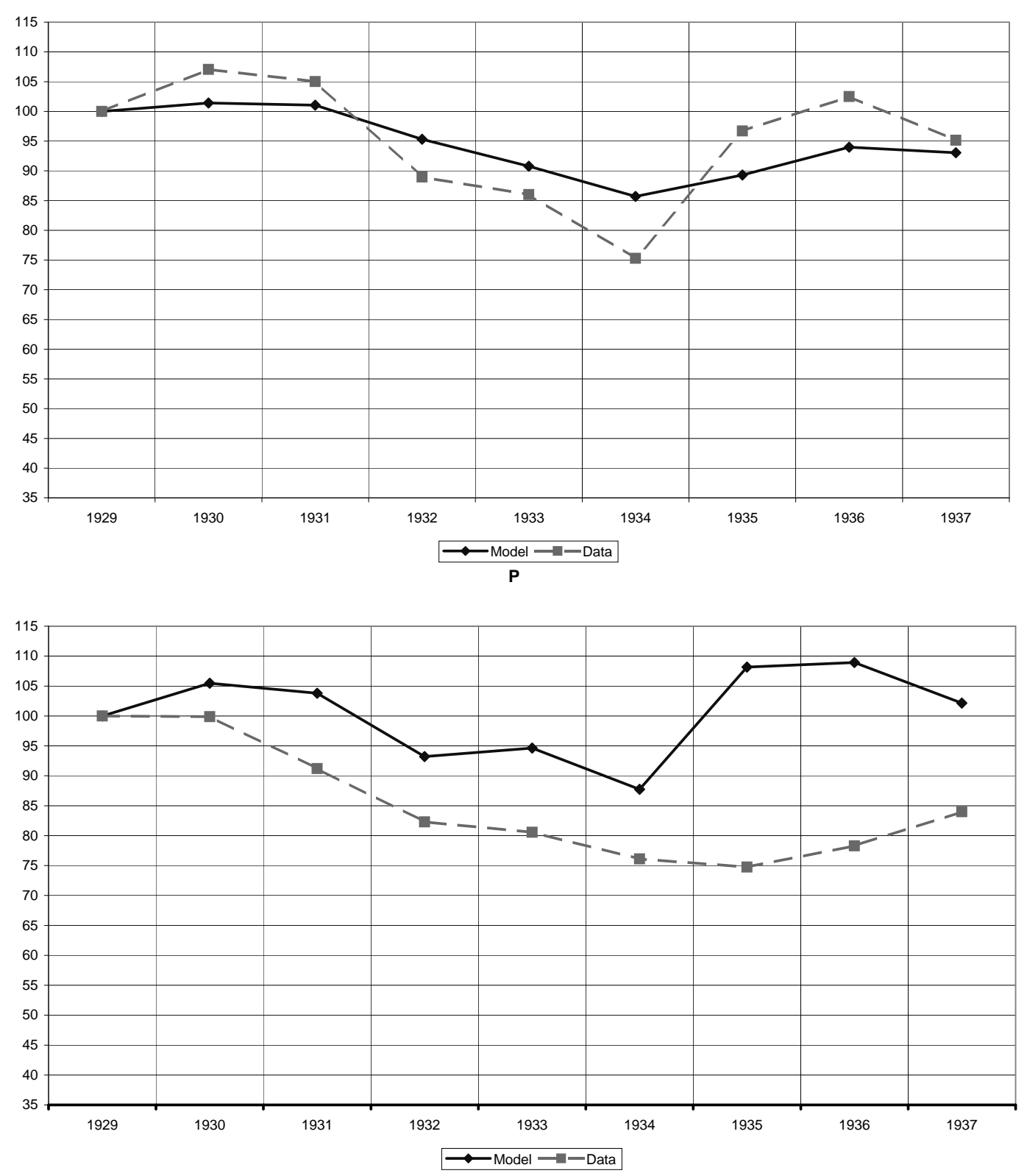

Figure 21: Simulation: model with sticky wages and monetary shocks versus actual data 
Detrended $Y$
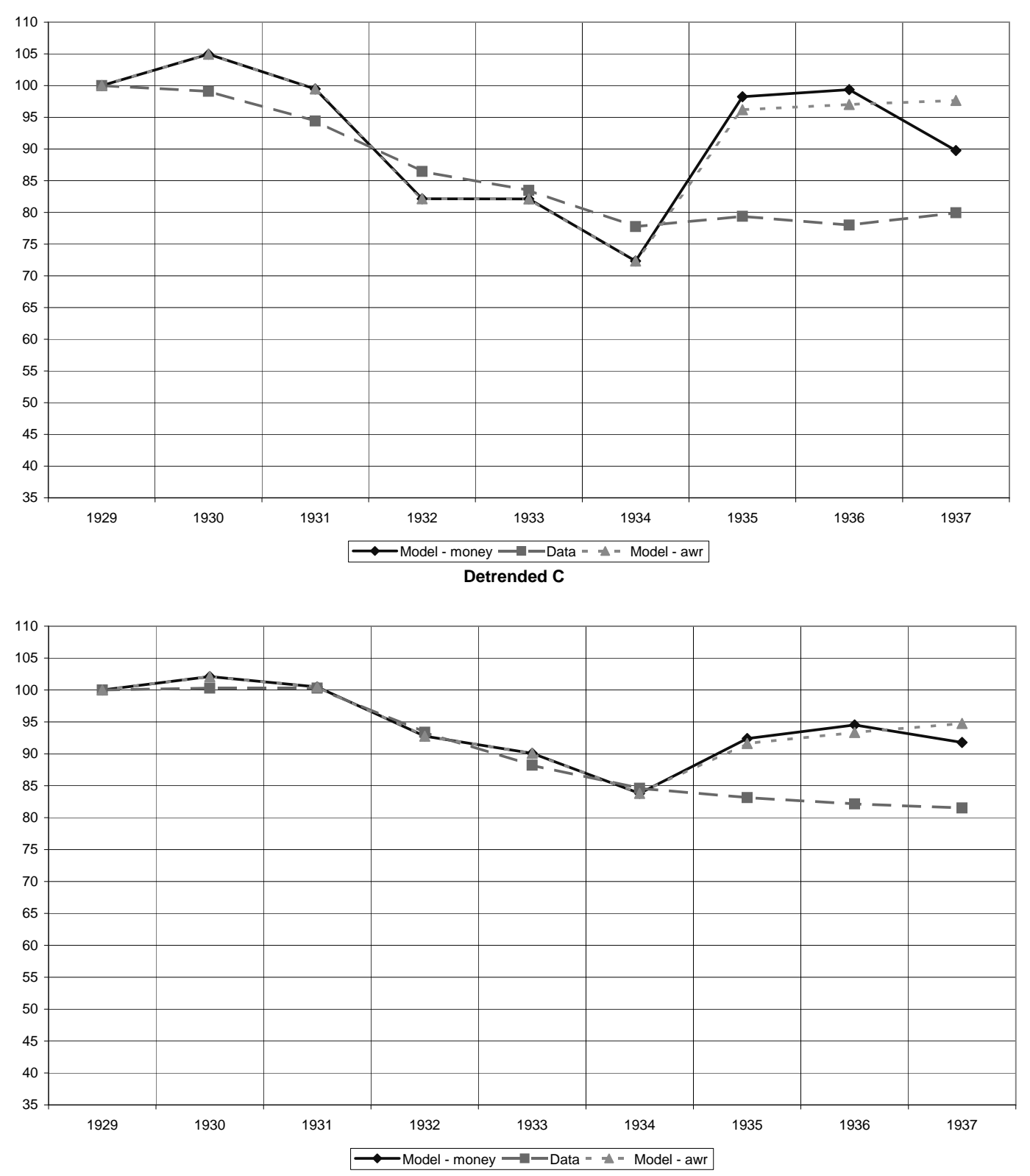

Figure 22: Simulation: model with monetary shocks, sticky wages until 1934 and competitive ones thereafter versus actual data 

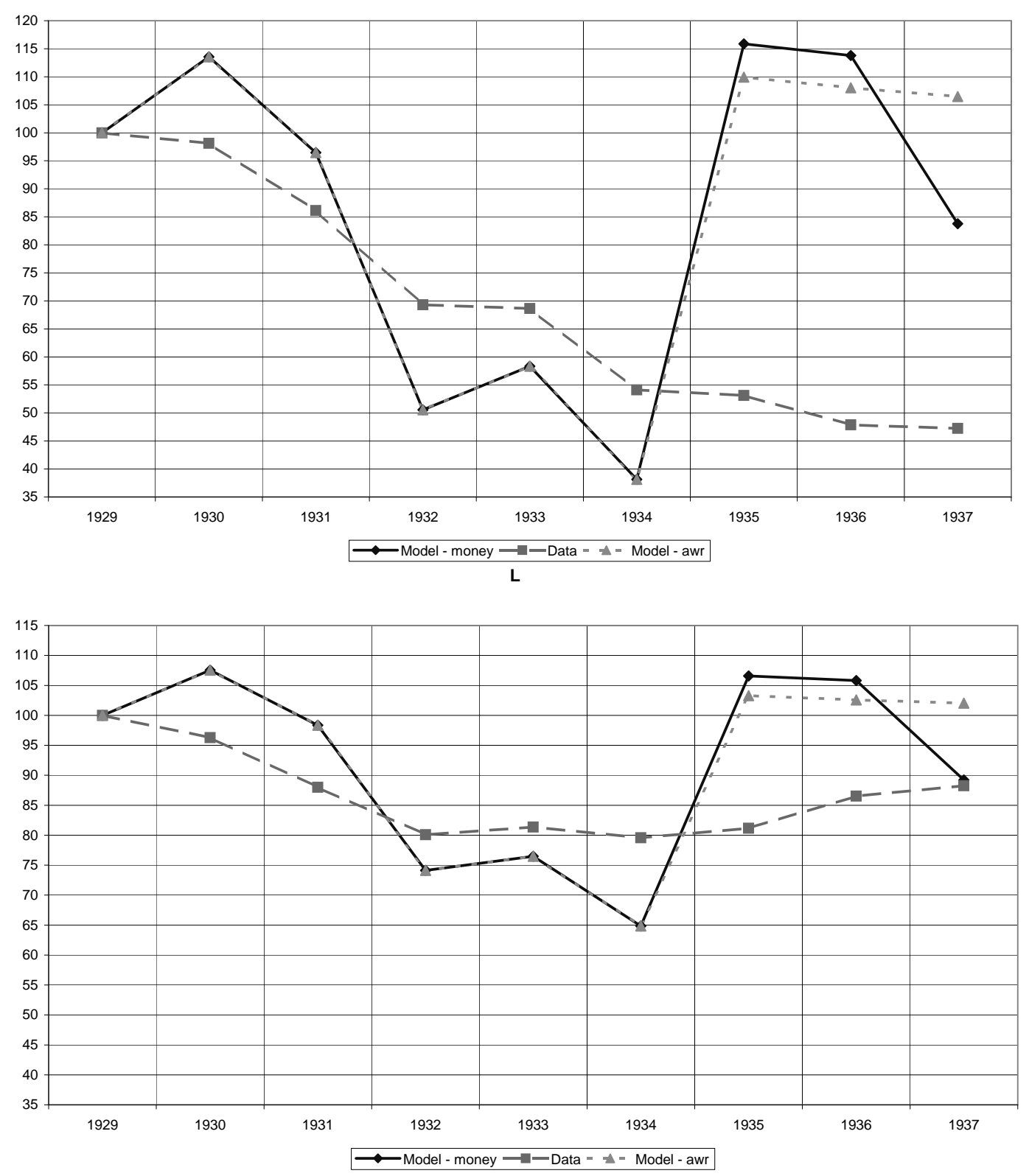

Figure 23: Simulation: model with monetary shocks, sticky wages until 1934 and competitive ones thereafter versus actual data 

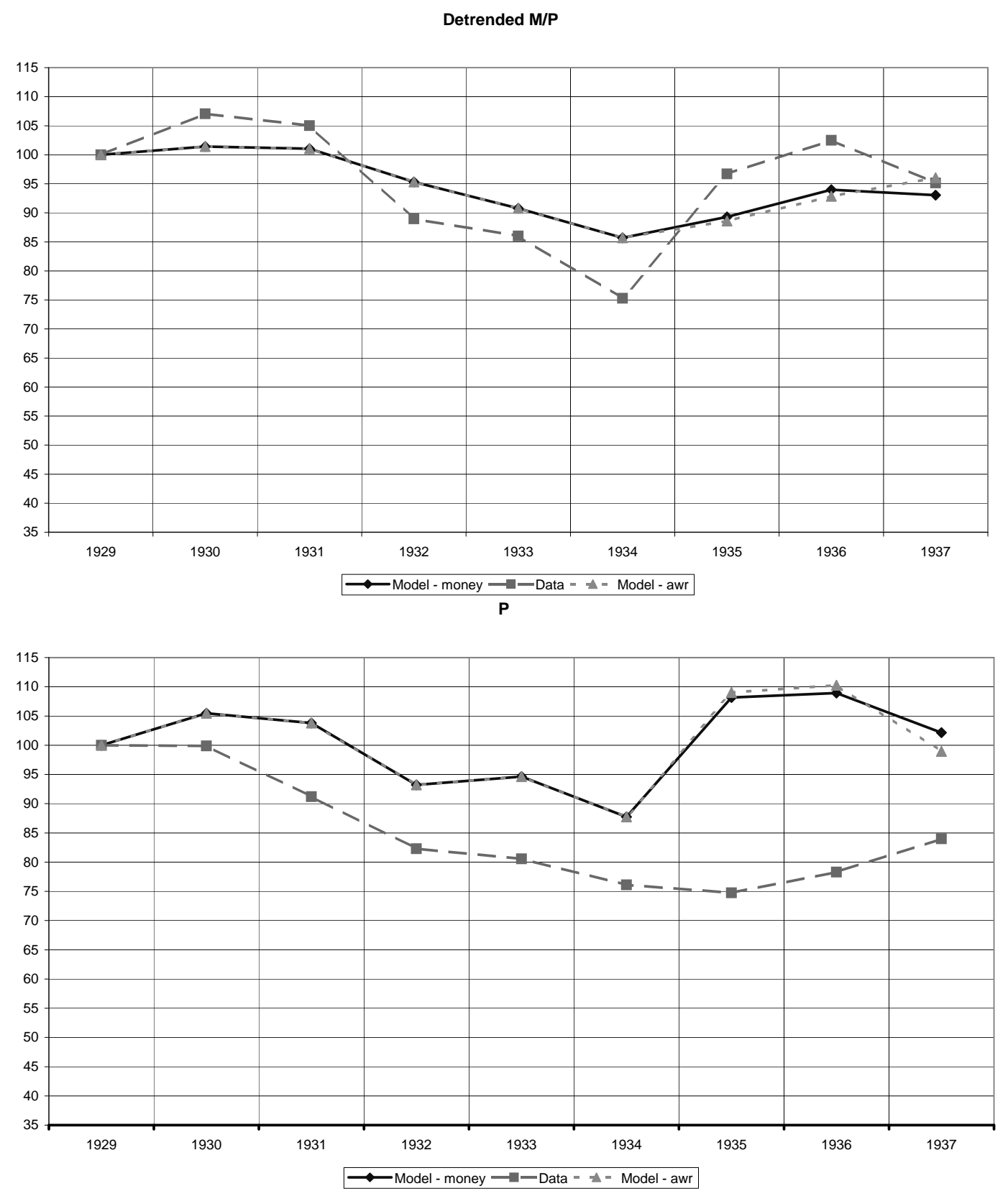

Figure 24: Simulation: model with monetary shocks, sticky wages until 1934 and competitive ones thereafter versus actual data 
Detrended W

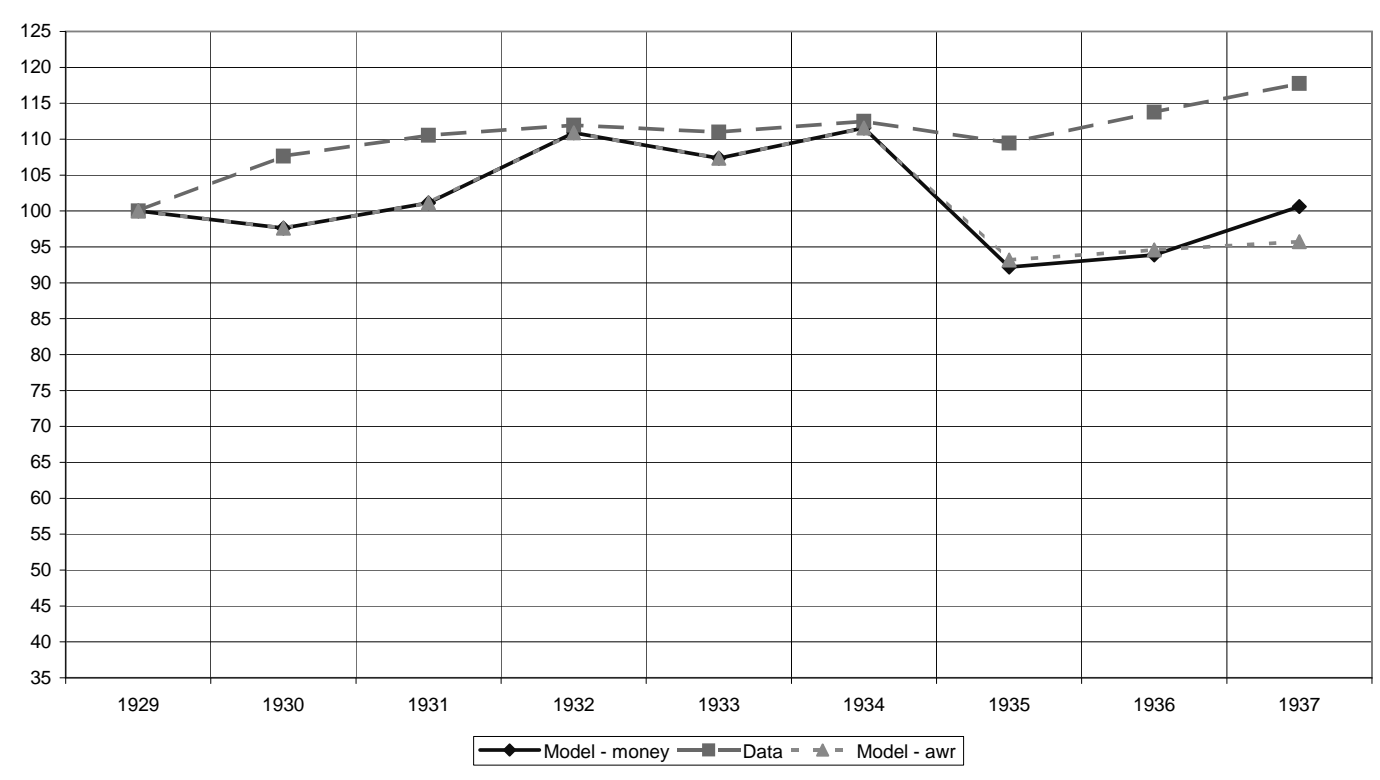

Figure 25: Simulation: model with monetary shocks, sticky wages until 1934 and competitive ones thereafter versus actual data 
Detrended Y
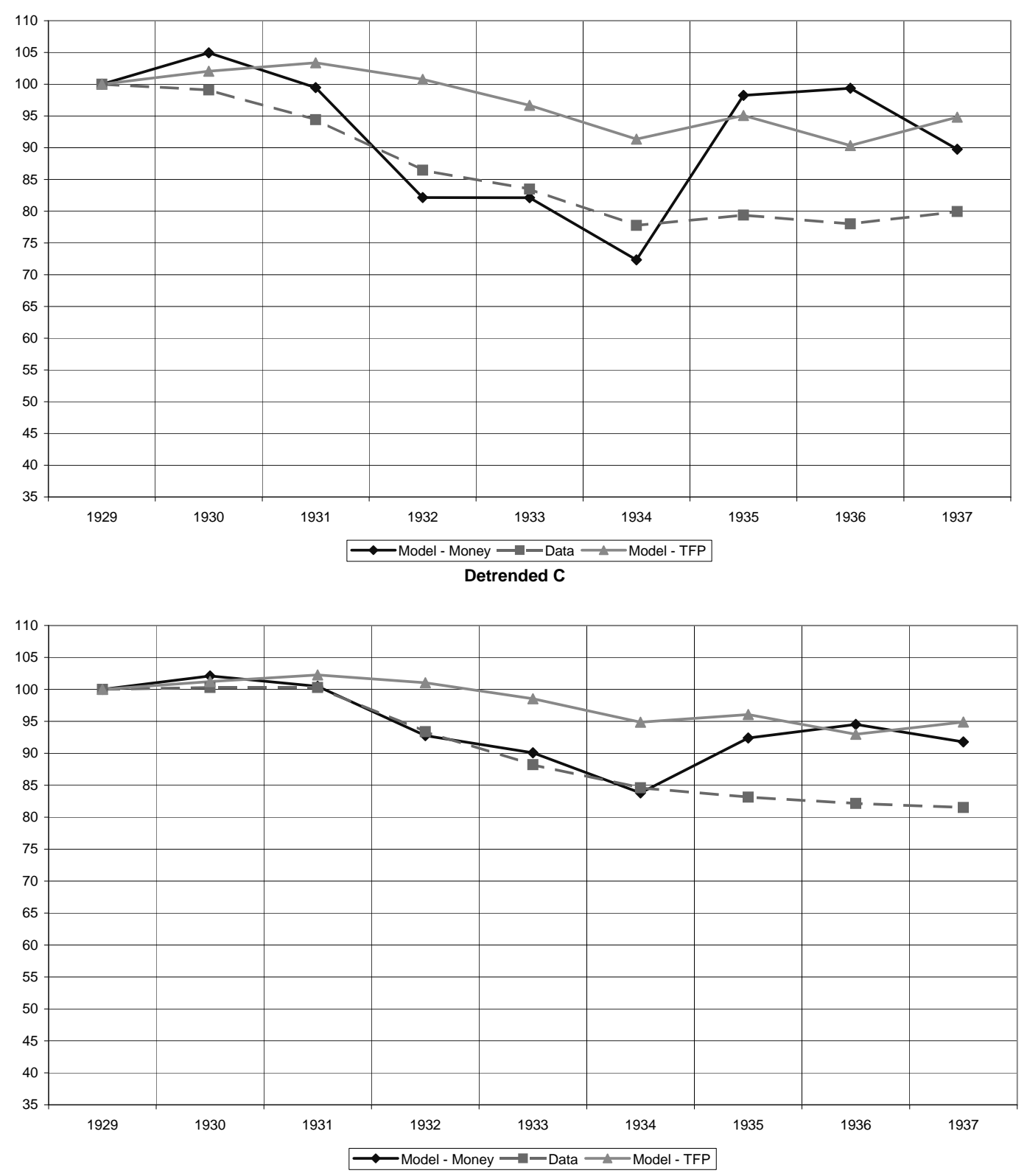

Figure 26: Simulation: model with sticky wages and monetary shocks, actual data, and model with sticky wages and TFP shocks 

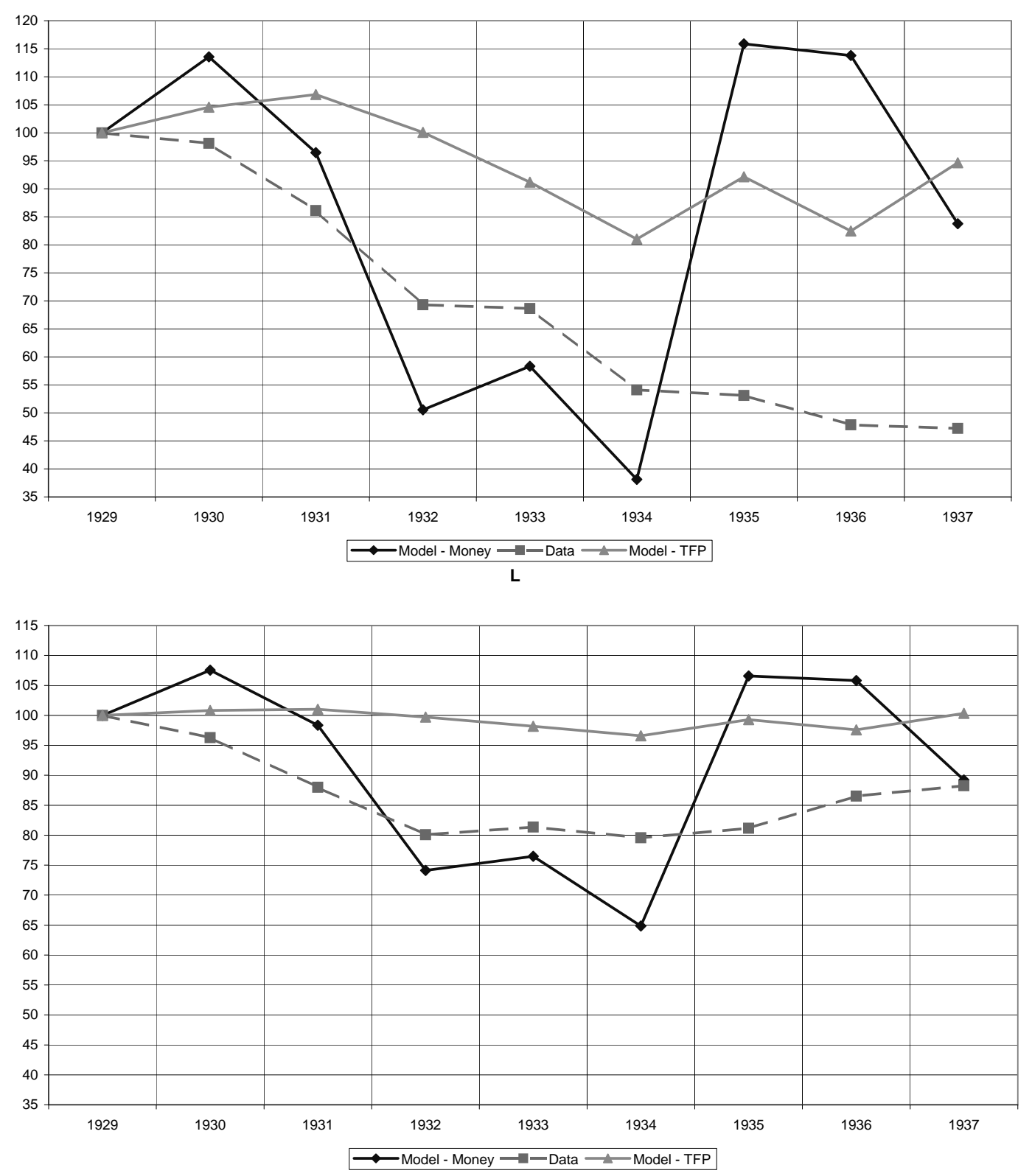

Figure 27: Simulation: model with sticky wages and monetary shocks, actual data, and model with sticky wages and TFP shocks 

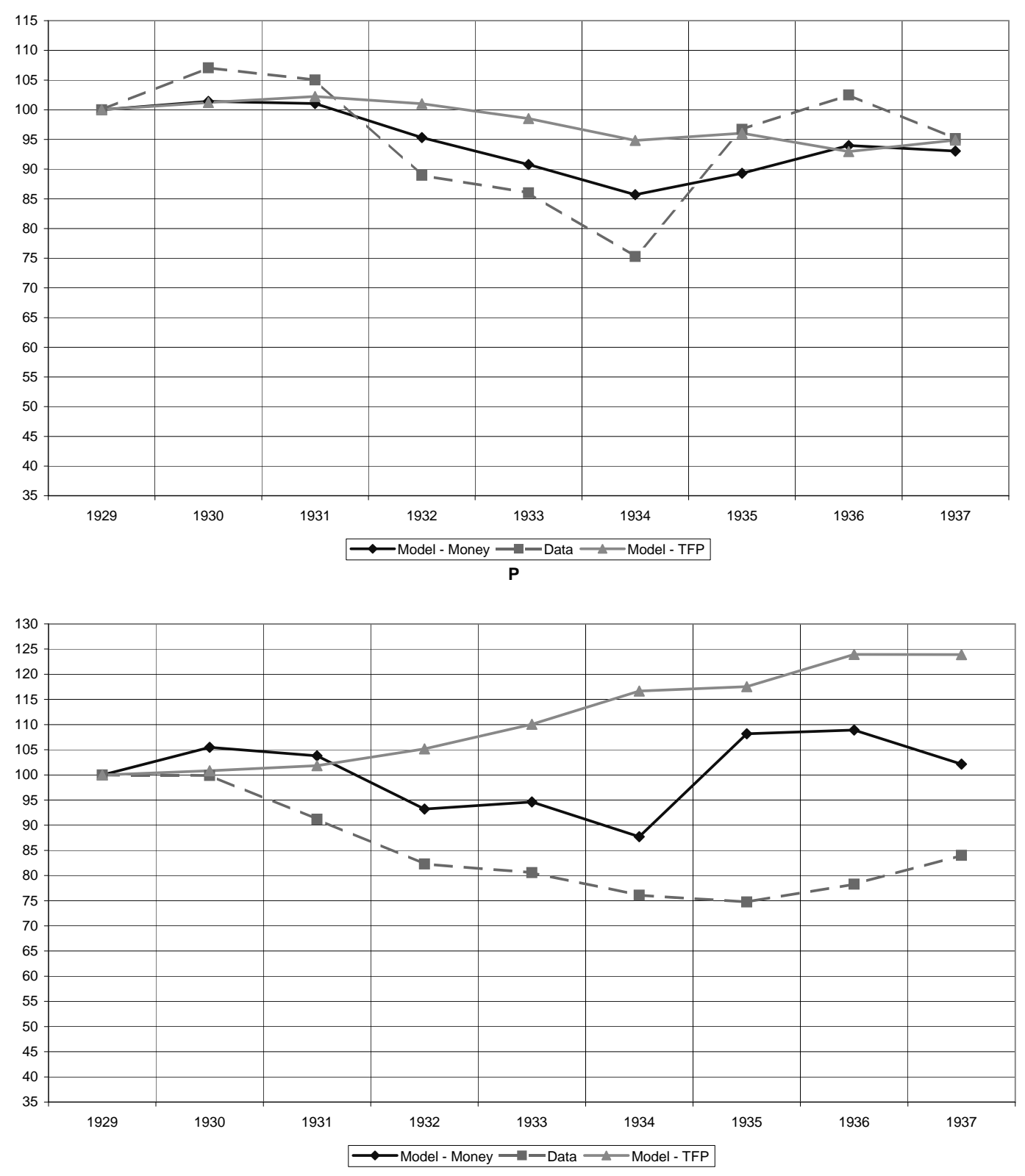

Figure 28: Simulation: model with sticky wages and monetary shocks, actual data, and model with sticky wages and TFP shocks 
Detrended W

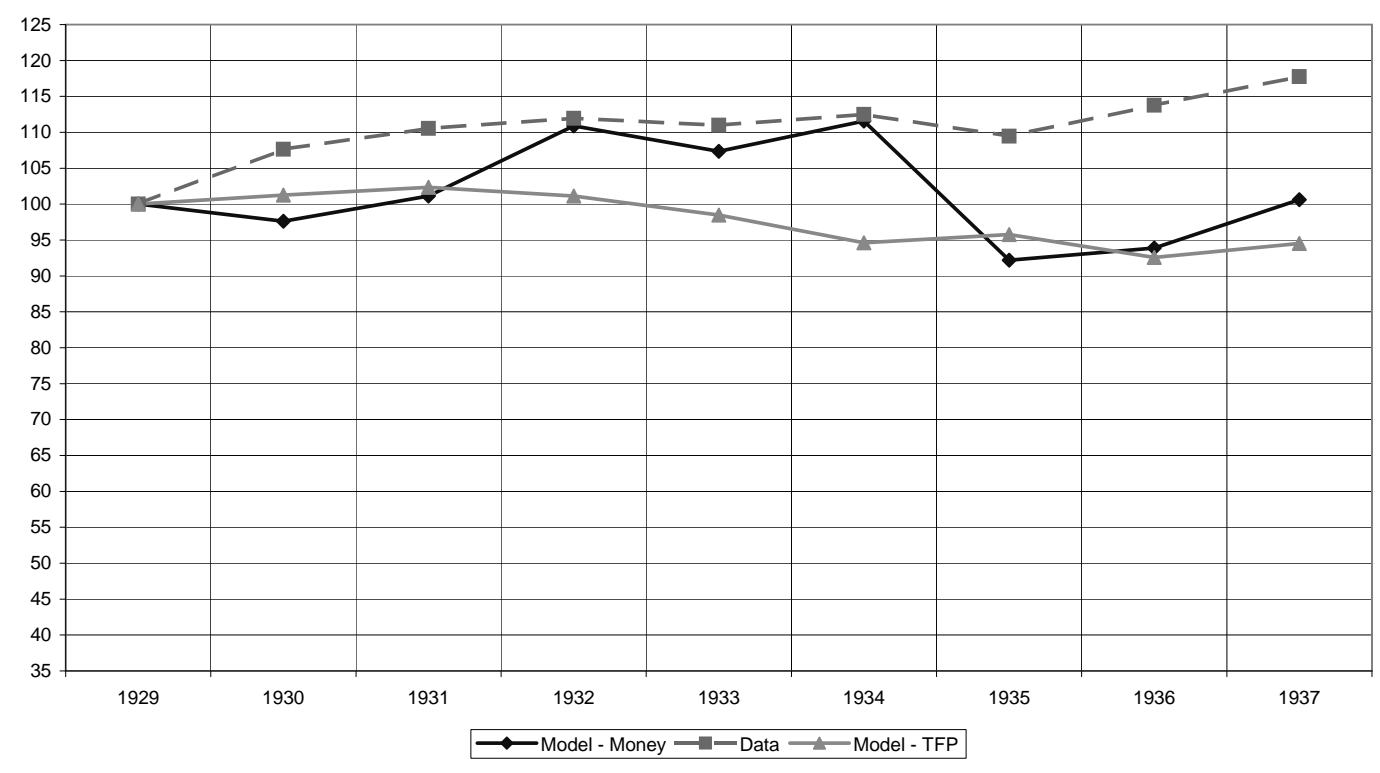

Figure 29: Simulation: model with sticky wages and monetary shocks, actual data, and model with sticky wages and TFP shocks 
Detrended $Y$
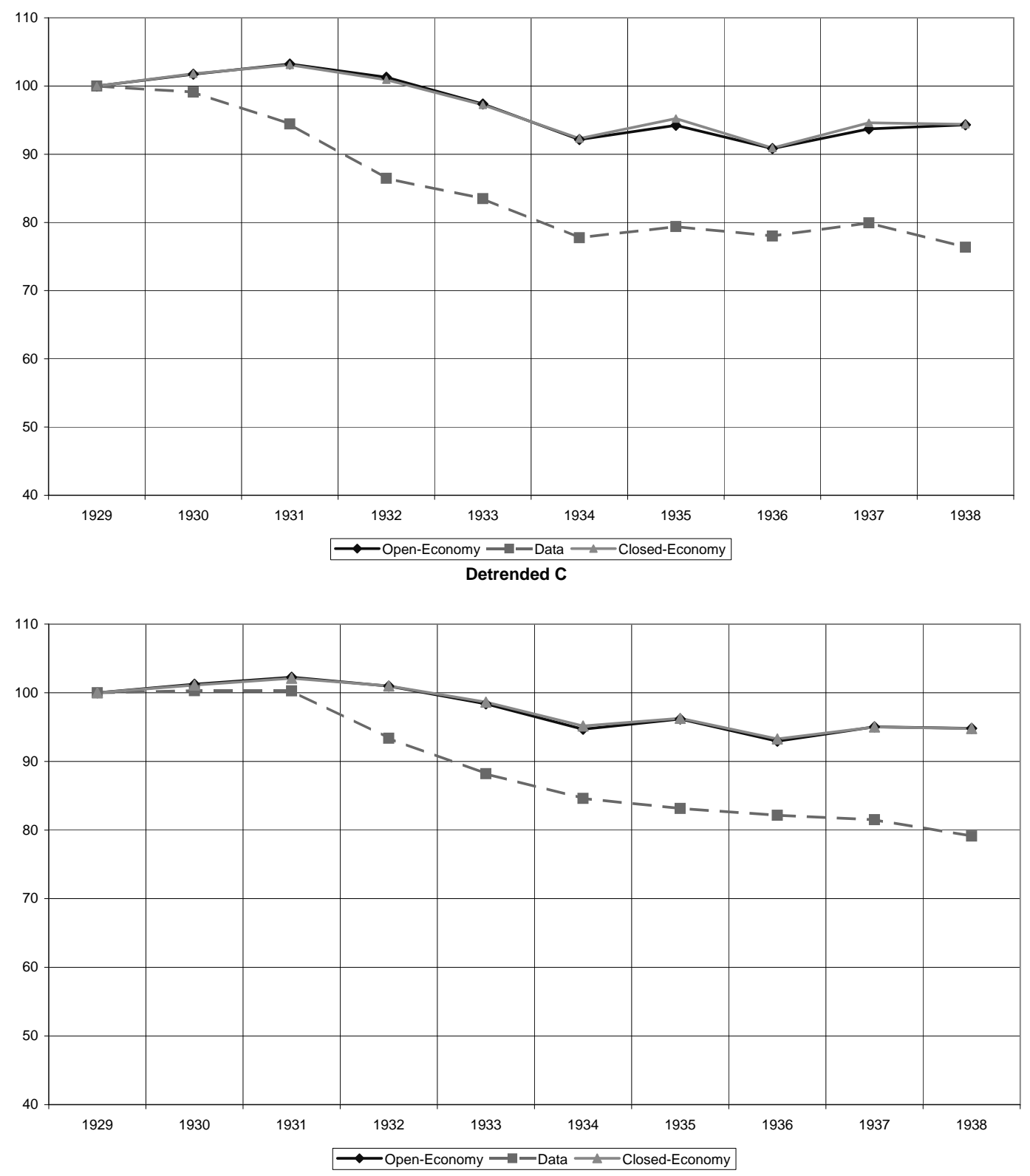

Figure 30: Simulation: RBC open-economy and closed-economy models versus the actual economy 

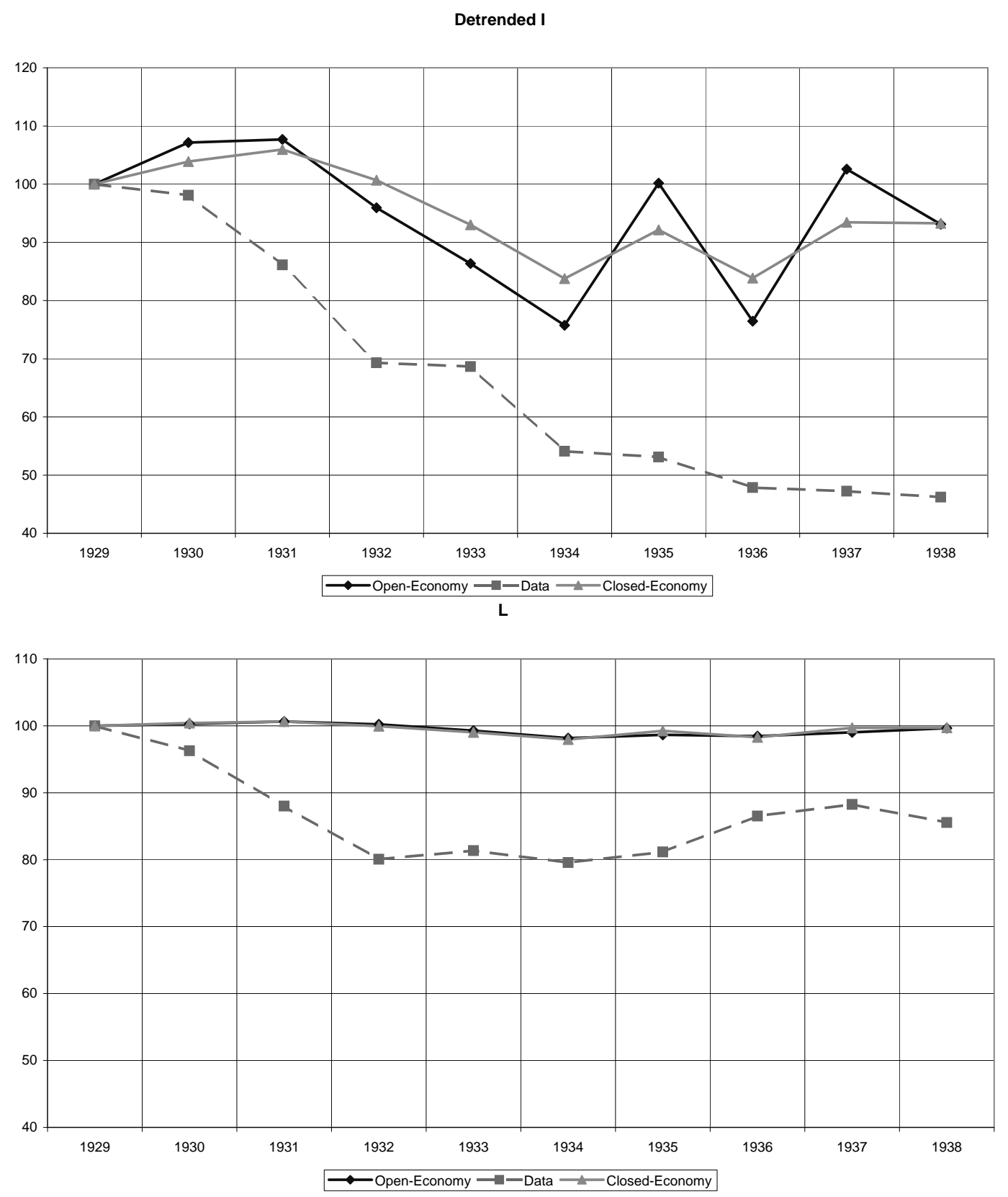

Figure 31: Simulation: RBC open-economy and closed-economy models versus the actual economy 
CA/Y

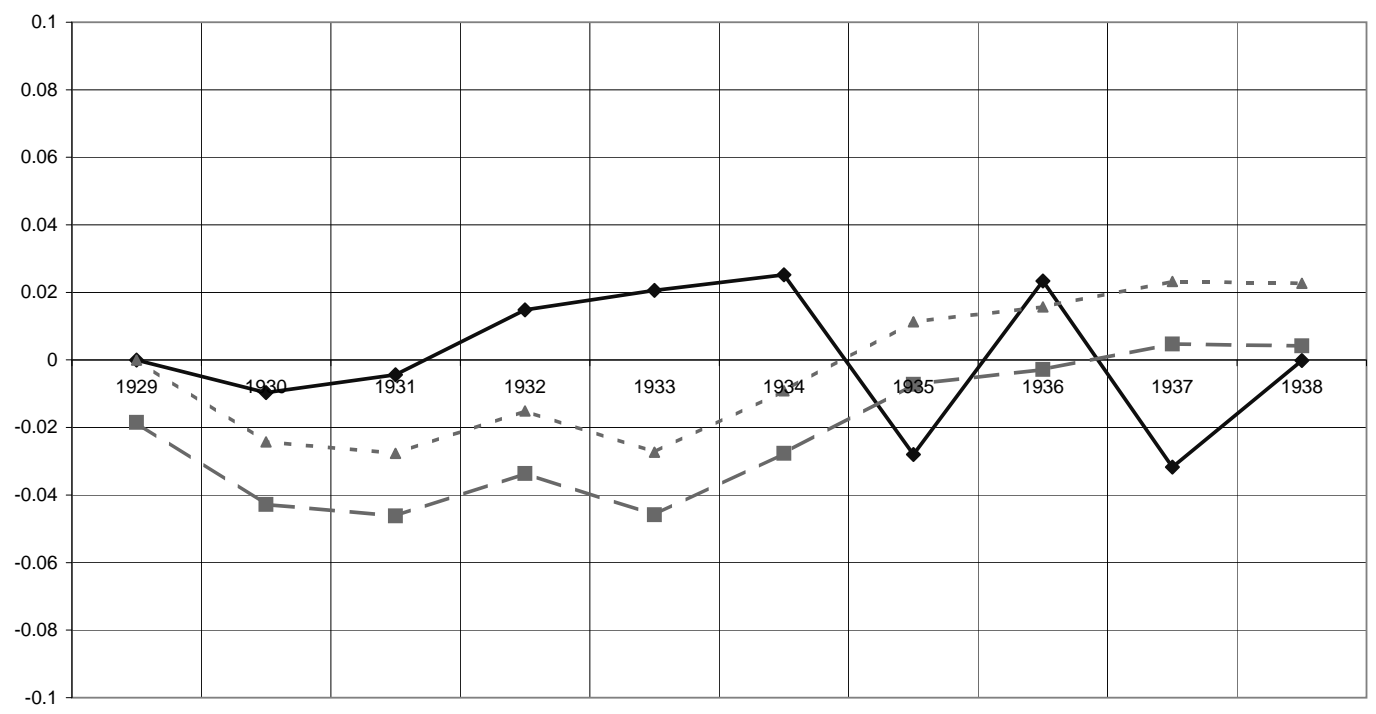

$\longrightarrow$-Model $\longrightarrow$-Data $=\stackrel{-}{-}$ Data $1929=0$

Figure 32: Simulation: RBC open-economy and closed-economy models versus the actual economy 
Detrended Y
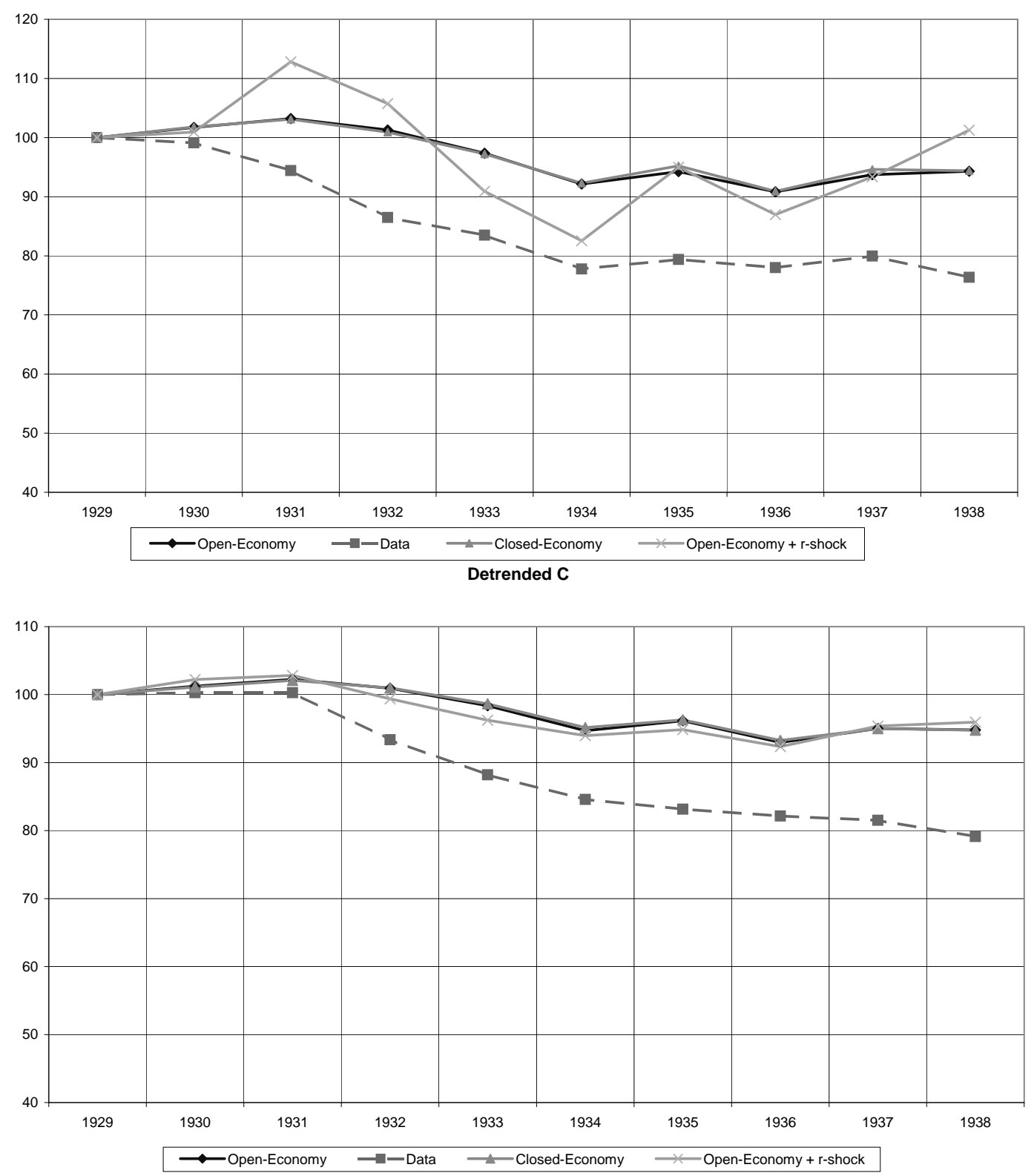

Figure 33: Simulation: comparative effects of international interest rate shocks 
Detrended I
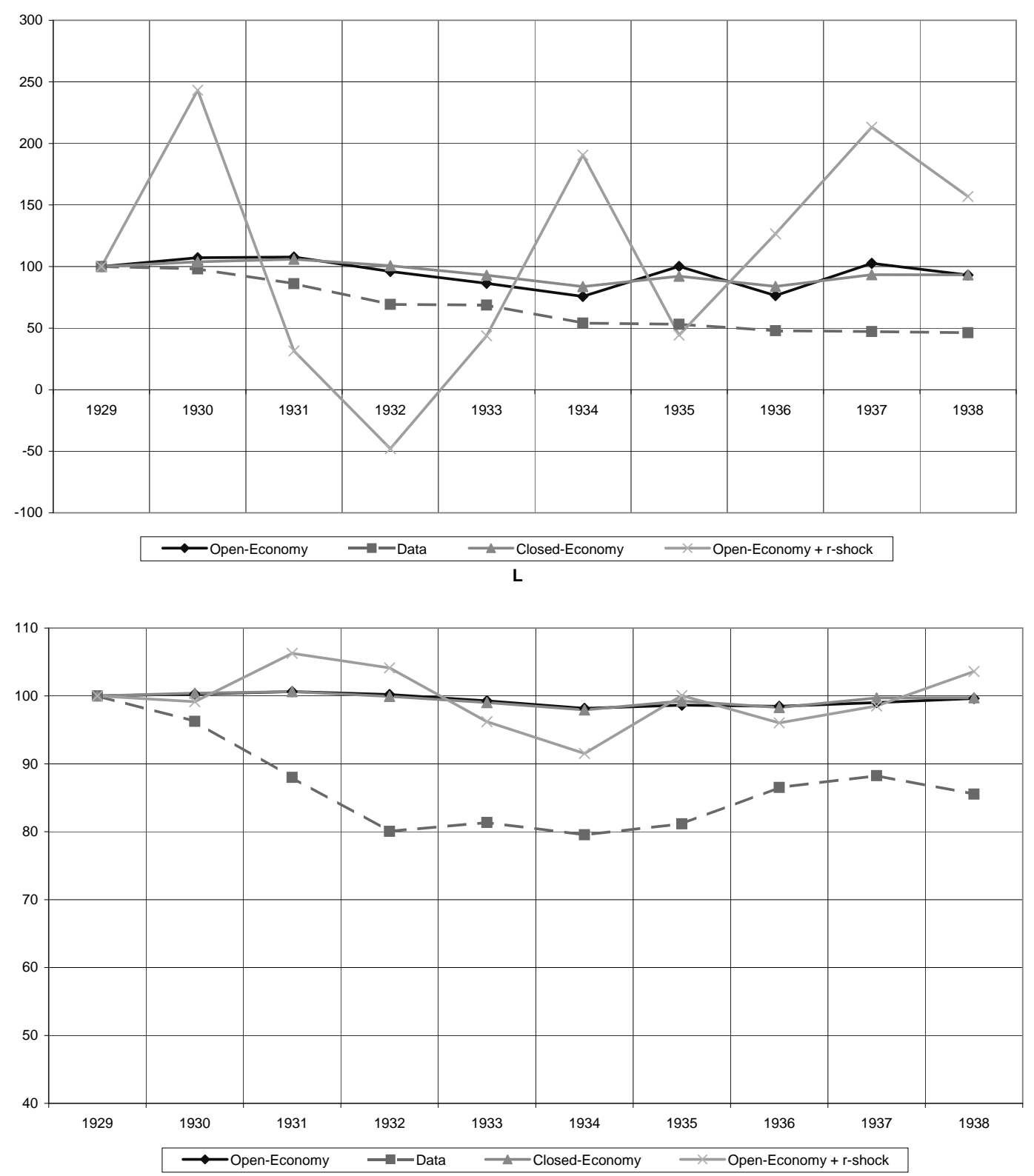

Figure 34: Simulation: comparative effects of international interest rate shocks 


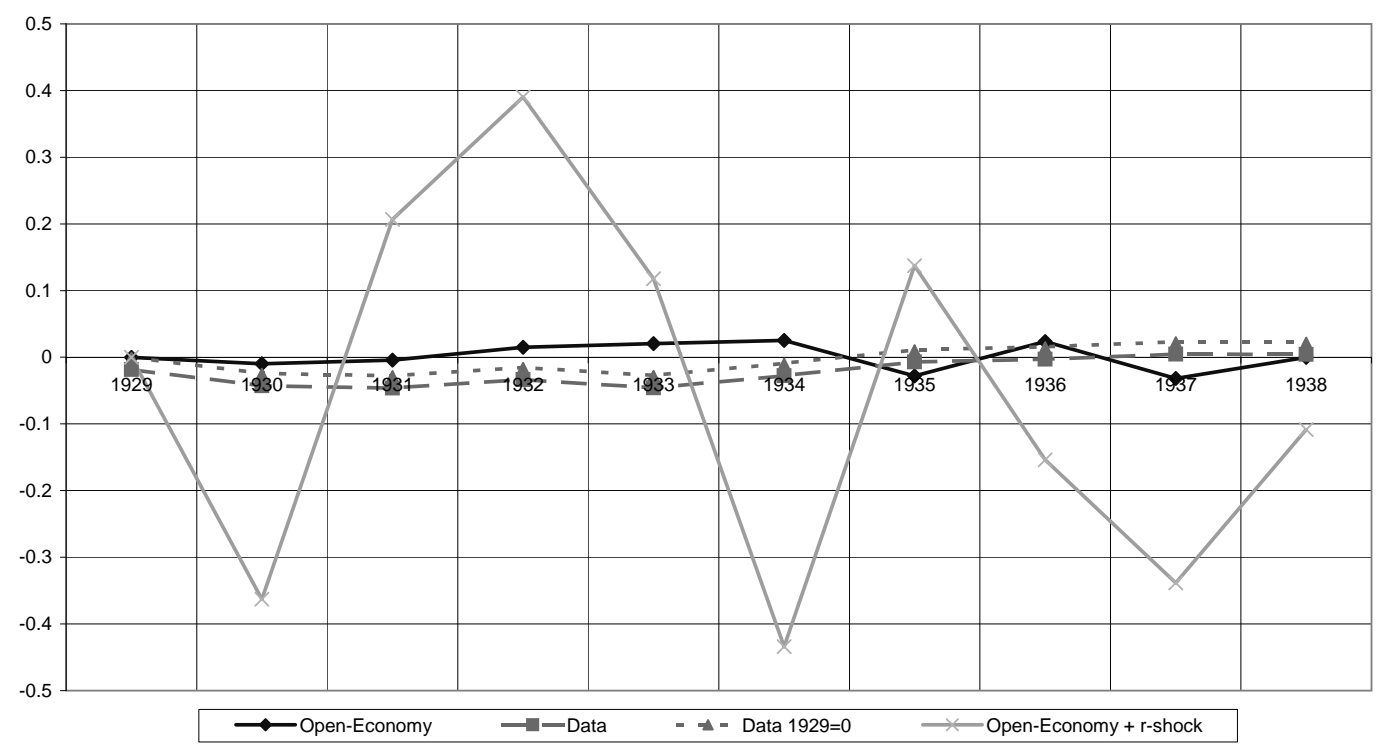

Figure 35: Simulation: comparative effects of international interest rate shocks

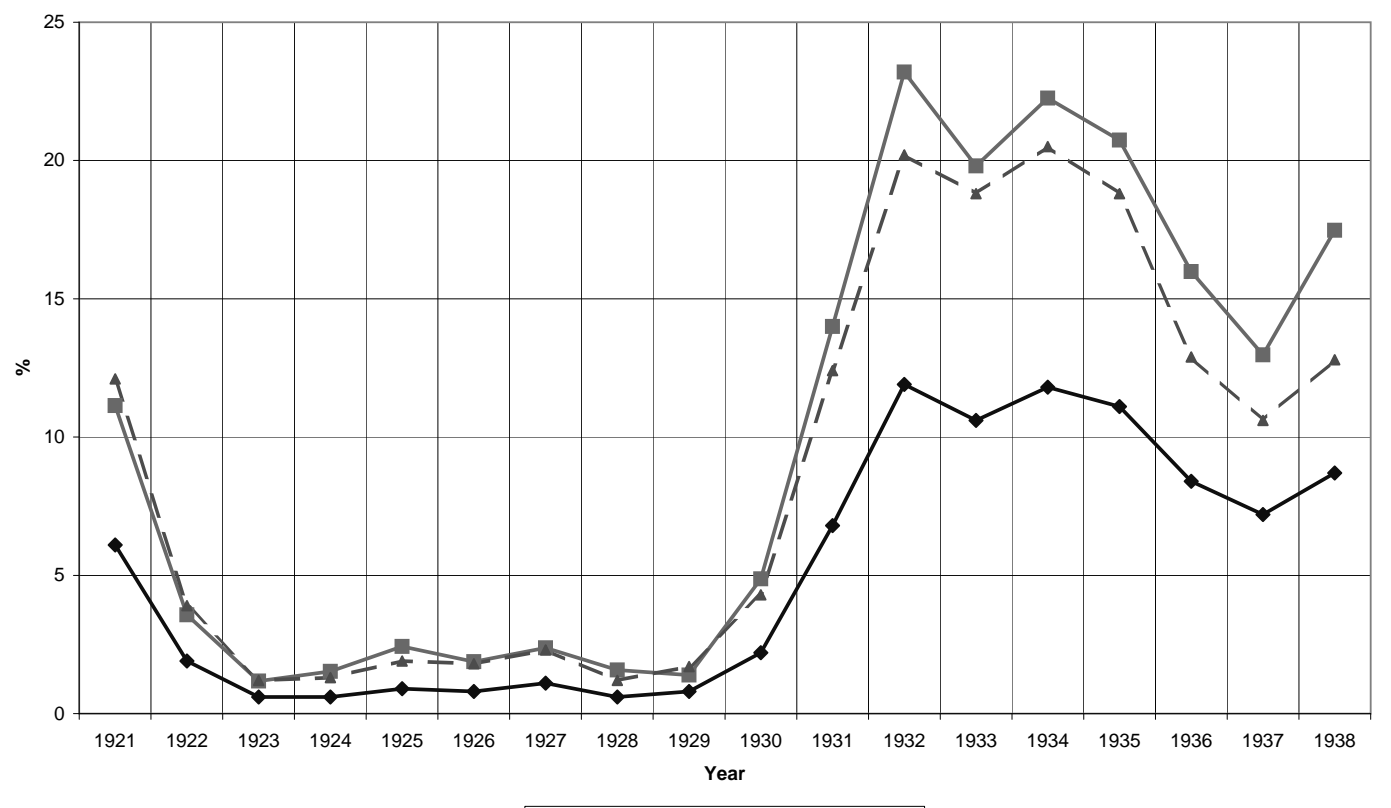

Figure 36: Unemployment rate: a comparison of different estimates. Sources: u Mad, Maddison (1995); u comp, yearly geometric mean of the monthly rate in Figure 4; u Gos, Goossens, Peeters, and Pepermans (1988) 


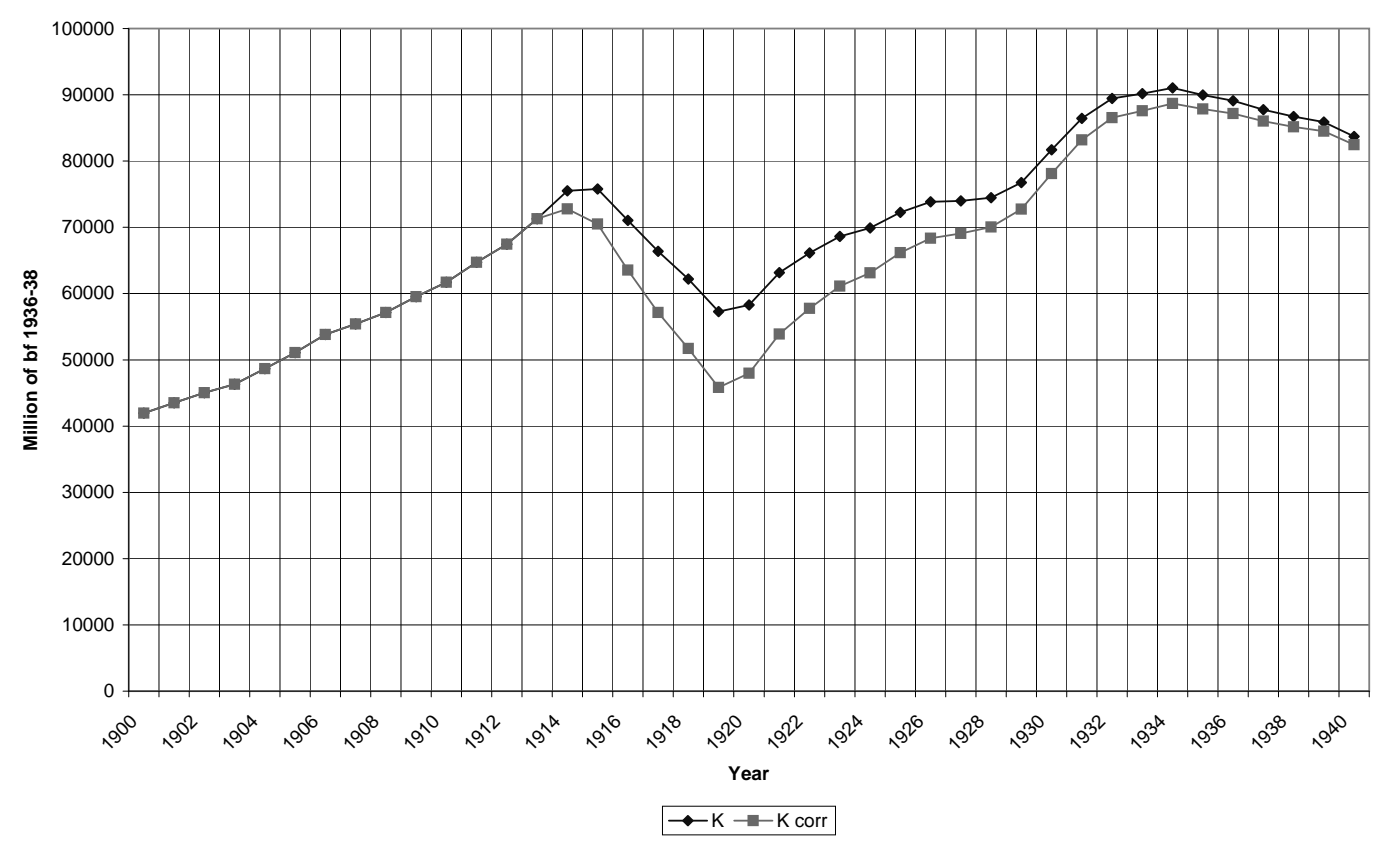

Figure 37: Capital before and after correcting for WWI. Source: My elaboration on van Meerten (2003) 
Département des Sciences Économiques de l'Université catholique de Louvain

Institut de Recherches Économiques et Sociales

Place Montesquieu, 3

1348 Louvain-la-Neuve, Belgique 